Small Long-Range Alpha Detector (LRAD) with Computer Readout 


\section{Composition and Layout by Randi Bagley, Group IS-5 \\ Illustrations by AnnMarie Dyson, Group IS-12}

An Affirmative Action/Equal Ouportunity Employer

This report was prepared as an account of work sponsored by an agency of the United States Government. Neither The Regents of the University of California, the United States Government nor any agency thereof, nor any of their employees, makes any warranty, express or implied, or assumes any legal liability or responsibility for the accuracy. completeness, or usefulness of any information, apparatus, product, or process disclosed, or represents that its use would not infringe privately owned rights. Reference herein to any specific commercial product, process, or service by trade name, trademark, manufacturer, or otherwise, does not necessarily constitute or imply its endorsement, recommendation, or favoring by The Regents of the University of California, the Linited States Government, or any agency thereof. The views and opinions of authors expressed herein do not necessarily state or reflect those of The Regents of the University of Califormia, the United States Government, or any agency thereof. 
Small Long-Range Alpha Detector (LRAD) with Computer Readout

D. W. MacArthur

K. S. Allander

J. A. Bounds

K. B. Butterfield

\section{MASTER}




\section{Table of Contents}

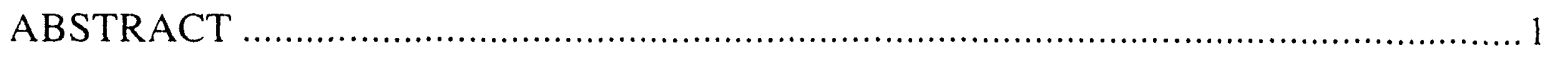

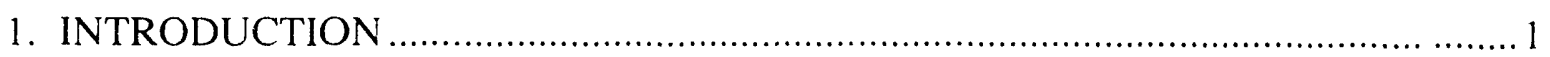

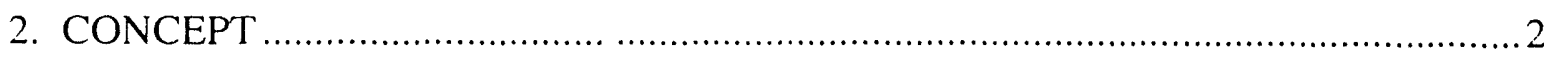

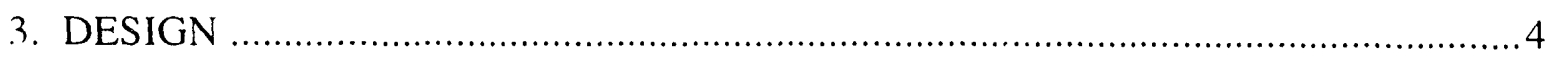

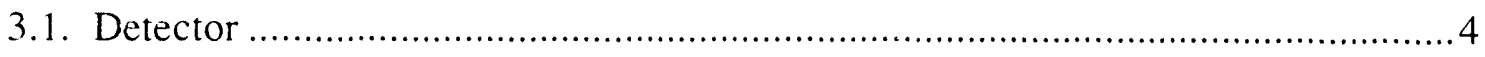

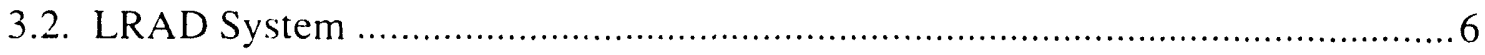

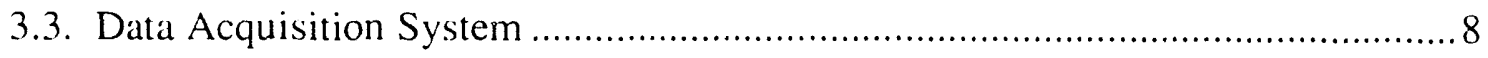

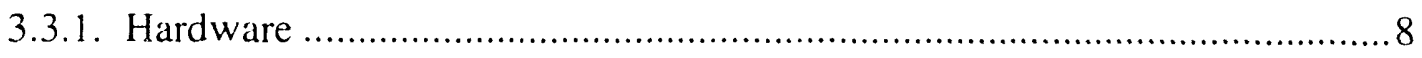

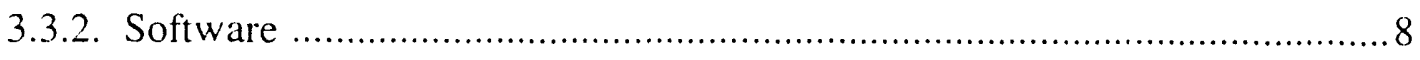

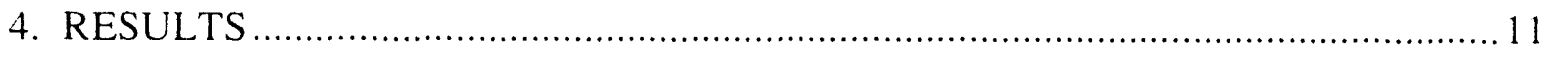

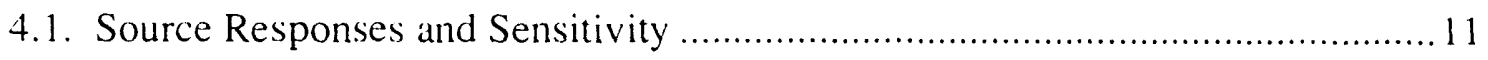

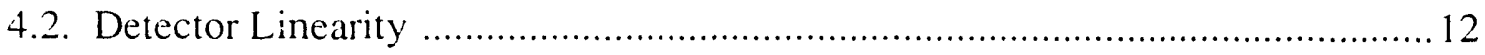

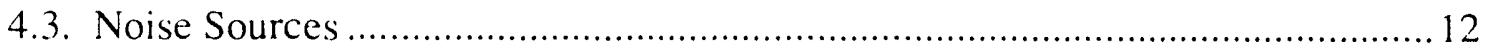

4.3.1. Potential dc noise sources and solutions ........................................... 13

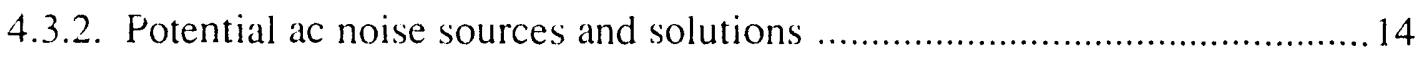

4.3.3. Transient noise (noise spikes) ....................................................... 15

4.4. Detection Gas ................................................................................... 15

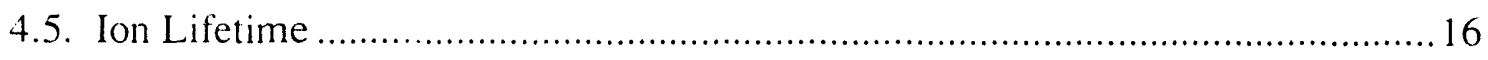

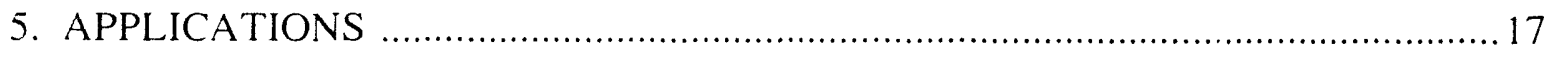

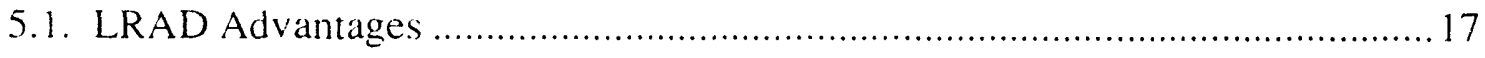

5.2. Specific Potential Applications ........................................................... 18

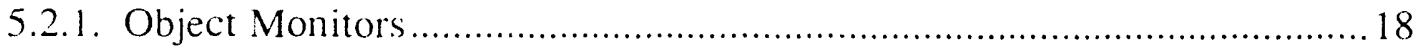

5.2.2. Personnel Safety Monitors ......................................................... 19

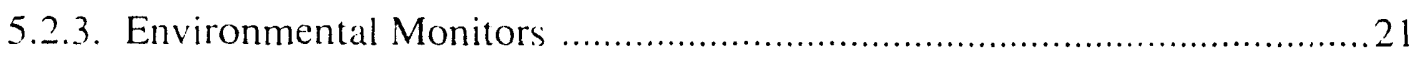

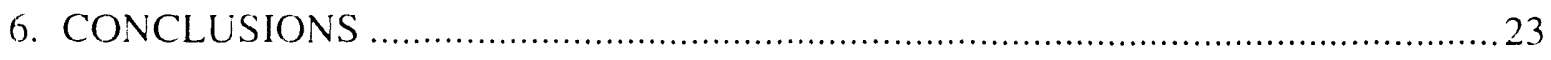

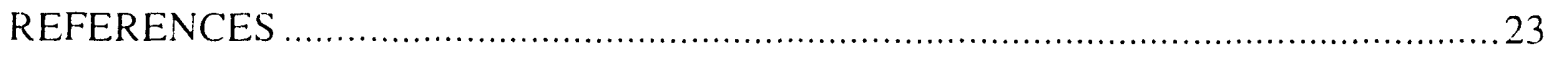




\title{
SMALL LONG-RANGE ALPHA DETECTOR (LRAD) WITH COMPUTER READOUT
}

\author{
by
}

D. W. MacArthur, K. S. Allander, J. A. Bounds, and K. B. Butterfield

\begin{abstract}
The small long-range alpha detector developed by N-2 was described in detail in the Los Alamos publication LA-12073-MS, "Long-Range Alpha Detector," published in 1991. Since publication of that report, a computerized data acquisition system has been added to the LRAD detector. In addition to detailing the new data acquisition system, we discuss new data generated with the enhanced system, including measurements of (1) ultimate sensitivity, (2) detector linearity, (3) ion lifetime, and (4) ion characteristics. Furthermore, we have expanded our understanding of ion recombination and statistical noise effects in the LRAD and have addressed them here as well as several proposed applications.
\end{abstract}

\section{INTRODUCTION}

All previous alpha contamination monitors have been severely restricted in their use by the relatively short range of alpha particles in air. The range of alpha particles is discussed in detail by Knoll': for our purposes, it is sufficient to note that the 4- to 5-MeV alpha particles emitted by common contaminants have a range of 2.5 to $3.5 \mathrm{~cm}$ in air. Lower energy alpha particles have an even shorter range. Because all traditional alpha monitors detect these alpha particles directly as shown in Fig. 1, the monitor must be held in close proximity to the contamination long enough for the alpha particles to register. Because the requirements for alpha contamination monitoring are often quite strict ${ }^{2}$ [for example, Department of Energy (DOE) Order 5480.11 specifies that transuranic alpha contamination should be measured at a level of 300 disintegiations per minute (dpm) over a $100-\mathrm{cm}^{3}$ areal, the monitor must be exposed to the contamination for several seconds for the alpha particles to register.

The proximity requirement makes it impossible to monitor contamination in confined spaces (such as cracks or gloves) that are smaller than the alpha monitor itself. Thoroughly monitoring the insides of equipment would require complete disassembly of each item; thus, equipment is often declared "potentially contaminated" because of where it has been used.

Standard alpha monitors can only detect contamination located in an area that can be covered by the detector (typically $100-$ to $300-\mathrm{cm}^{2}$ ); large surfaces must be scanned very slowly to indicate contamination. Traditional detectors will only detect "hot spots" on the surface, and uniform, very low-level contamination will be missed. 


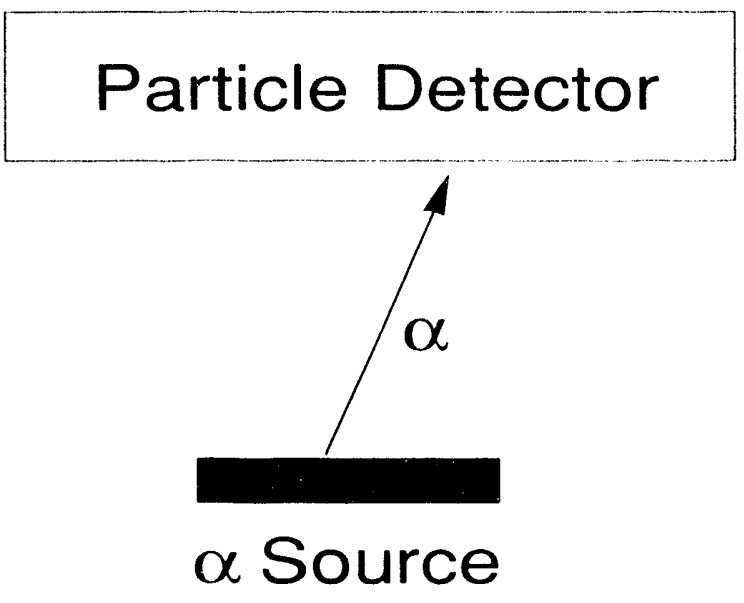

Fig. 1. Traditional alpha detectors detect the alpha particle directly.

Presently, alpha detectors cannot reliably meet the sensitivity limits imposed by DOE orders. Under optimum conditions, a traditional alpha detector will eventually detect 100- to 300-dpm sources. However, contamination monitoring rarely takes place under optimum conditions, so effective monitoring is often impossible.

Finally, traditional personnel and equipment scanning is often performed using handheld monitors. In this case, the effectiveness of the scan depends strongly on the skill and attention of the individual doing the monitoring. If large surfaces or many objects are being scanned, then the end of the scan is likely to be much less thorough than the start.

The aforementioned limitations of conventional alpha detectors can be summarized as four problems. Traditional alpha detectors are

(1) unable to monitor inside small spaces,

(2) unable to efficiently monitor large surfaces,

(3) insufficiently sensitive, and

(4) non-automated.

In a previous report, ${ }^{3}$ the long-range alpha detector (LRAD) was originally proposed as a solution for all of these problems. Here, we further document the performance of the prototype LRAD system, especially the computerized data acquisition system, as well as documenting our understanding of the ion-detection process. We also describe in detail a number of potential applications that take advantage of the LRAD's unique characteristics.

\section{CONCEPT}

A brief description of the LRAD concept, detailed in a previous repon, ${ }^{3}$ will be included here. The main mechamism for alpha particle energy loss in air is creation of ion pairs. (Actually the alpha particle creates a positive ion and a free electron that rapidly attaches itself to a neutral gas atom. so both positive and negative ions can be observed.) 
In air, each electron/ion pair requires $35 \mathrm{eV}$ to create, ${ }^{1}$ so a typical $5-\mathrm{MeV}$ alpha particle will create about 150000 ion pairs. As illustrated in Fig. 2, the ionized molecules can be transportcel by a moving air current into a flow-through ion chamber. The charges deposited by the ions in the chamber are measured as a dc current in the electrometer. The ion chamber is not acting in a more usual particle detecting mode, but rather as a simple charge collector. Figure 3 is a schematic of the "two grid" ion chamber used in our present experiments. A voltage (in our case, generated by a $300-\mathrm{V}$ battery) is applied to the second grid, and the current from the first grid is measured by a sensitive current meter (a Keithley 617 electrometer). The electric field created between the two grids sweeps either the positive or negative ions (depending on the polarity of the voltage source) onto the signal grid; charge deposited on the signal grid can be measured as a current flow between that grid and the grounded enclosure. If the voltage applied to the second grid is positive, then negative ions are collected on the signal grid and vice versa. For maximum noise immunity, both the voltage supply and the current meter should be floating with respect to ground (the battery is floating but the electrometer is not), and the entire system should be grounded only at a single point, ${ }^{4}$ as shown in Fig. 3. True singlepoint grounding may be impossible, but the number of separate ground connections should be reduced to the minimum.

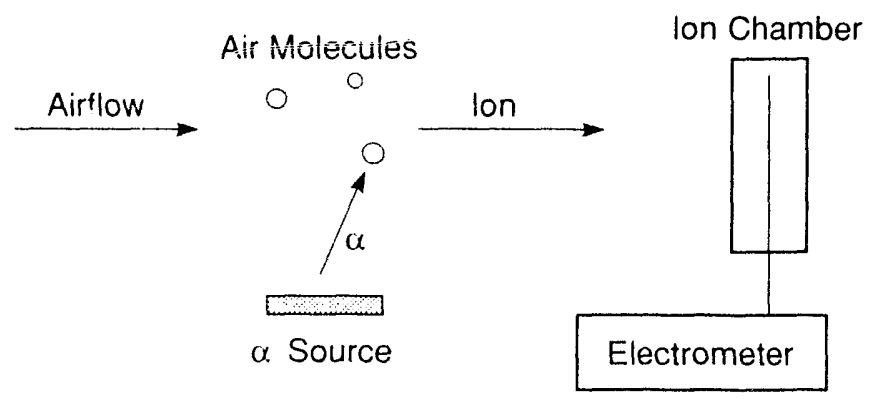

Fig. 2. The LRAD detects the alpha source indirectly through air ionization.

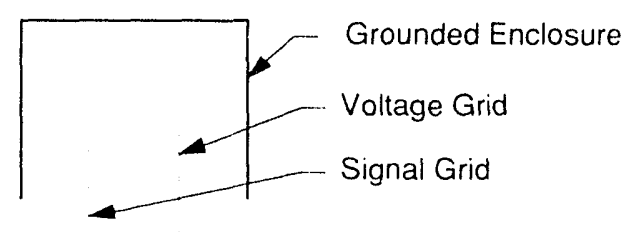

Airflow

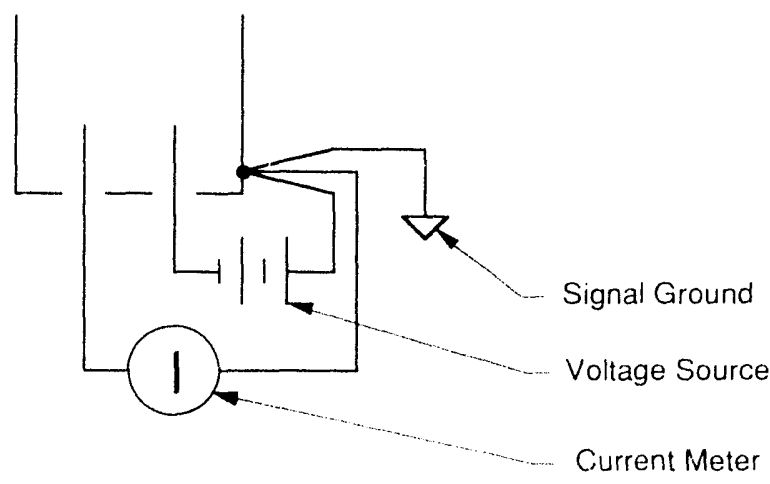

Fig. 3. Schematic representation of a two-grid LRAD. 


\section{DESIGN}

\subsection{Detector}

The LRAD detector comprises three major components (see Fig. 4): the fan box, the ion detector box, and the air inlet. The fan box encloses the fan assembly which draws air through the ion detector. The ion detector box contains the high-voltage (HV) grid and the two signal grids; it is the most delicate part of the detector. The air inlet transports the ions from the sample enclosure (Sec. 3.2) into the ion detector. The three components of the LRAD are described in detail in the following paragraphs and illustrated in Figs. 5 - 7.

The fan box (Fig. 5) is built in a Pomona Electronics Box measuring 6 in. by $?$ in. by 1.5 in. A 1.25-in. hole is punched out of the back panel, and a 1.5-in. hole is punched out of the front. The fan draws air in through the front hole and exhausts it through the rear. A 1-9/16-in.-diam. 12-Vdc brushless fan (Radio Shack model no. 273-244) is mounted on the back plate inside the box. This fan is controlled by a rocker switch, an LED, and a 3/32-in. subminiature power jack mounted on one side of the box.

The ion detector illustrated in Fig. 6 is built in a Pomona Electronics Box with the same dimensions as the fan box. A 1.5-in. hole is punched out of both the front and back panels. These holes allow ionized air to be drawn into the ion detector, where the ions are collected on the signal grid. Three mesh grids (constructed of 0.017 -in. brass wire and measuring 2.75 in. by 4.5 in.) are mounted on 1/8-in.-diam. teflon standoffs inside the Pomona hox. Although these standoffs limit leakage current substantially, the really small leakage currents $(\leq 10 \mathrm{fA}$ ) required in this application can only be achieved by mounting the HV and signal grids on separate standoffs that, in turn, are mounted cn the grounded enclosure. In this way, leakage current from the HV grid flows directly to ground without passing through the signal grid. If the $\mathrm{HV}$ is $300 \mathrm{~V}$ and the offset voltage of the electrometer is $\geq 5 \mathrm{mV}$, then the special mounting results in about $10^{5}$ reduction in leakage current on the signal grid. As shown in Fig. 6, HV is applied to the center grid, and an ion signal is retrieved from the front grid. The third grid was originally intended as a possible second signal grid, but initial data indicated that not only was the rear grid not contributing to the ion signal, but it was contributing a large amount of noise to the

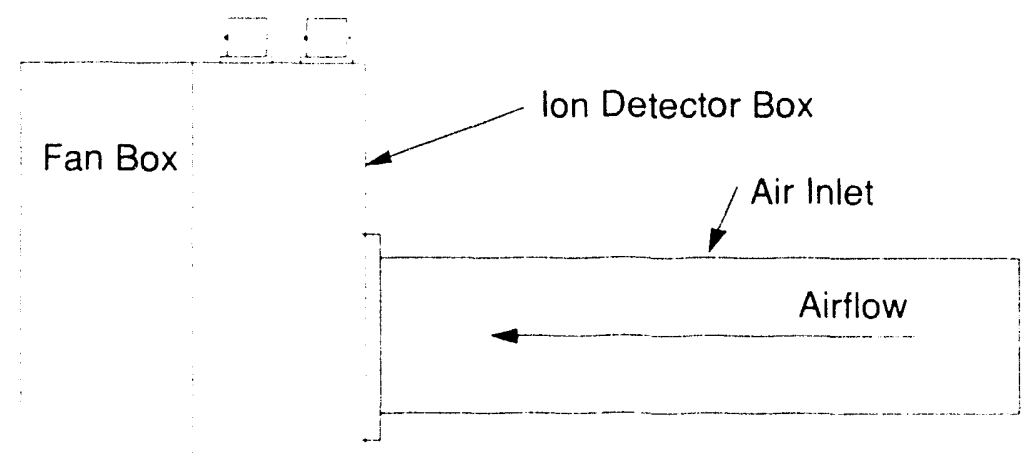

Fig. 4. Plan view of the three major components of the LRAD detertor. 


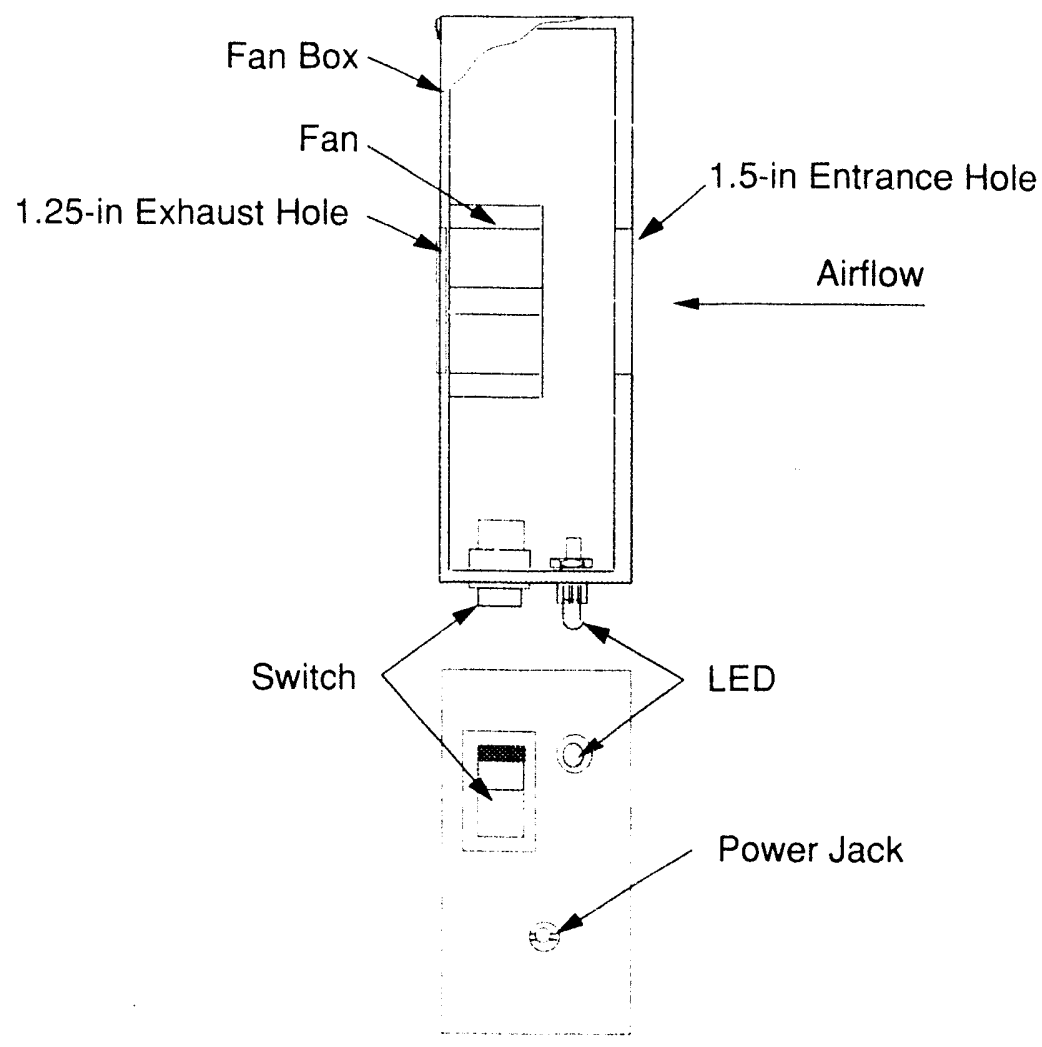

Fig. 5. Interior and control panel views of the fan box.

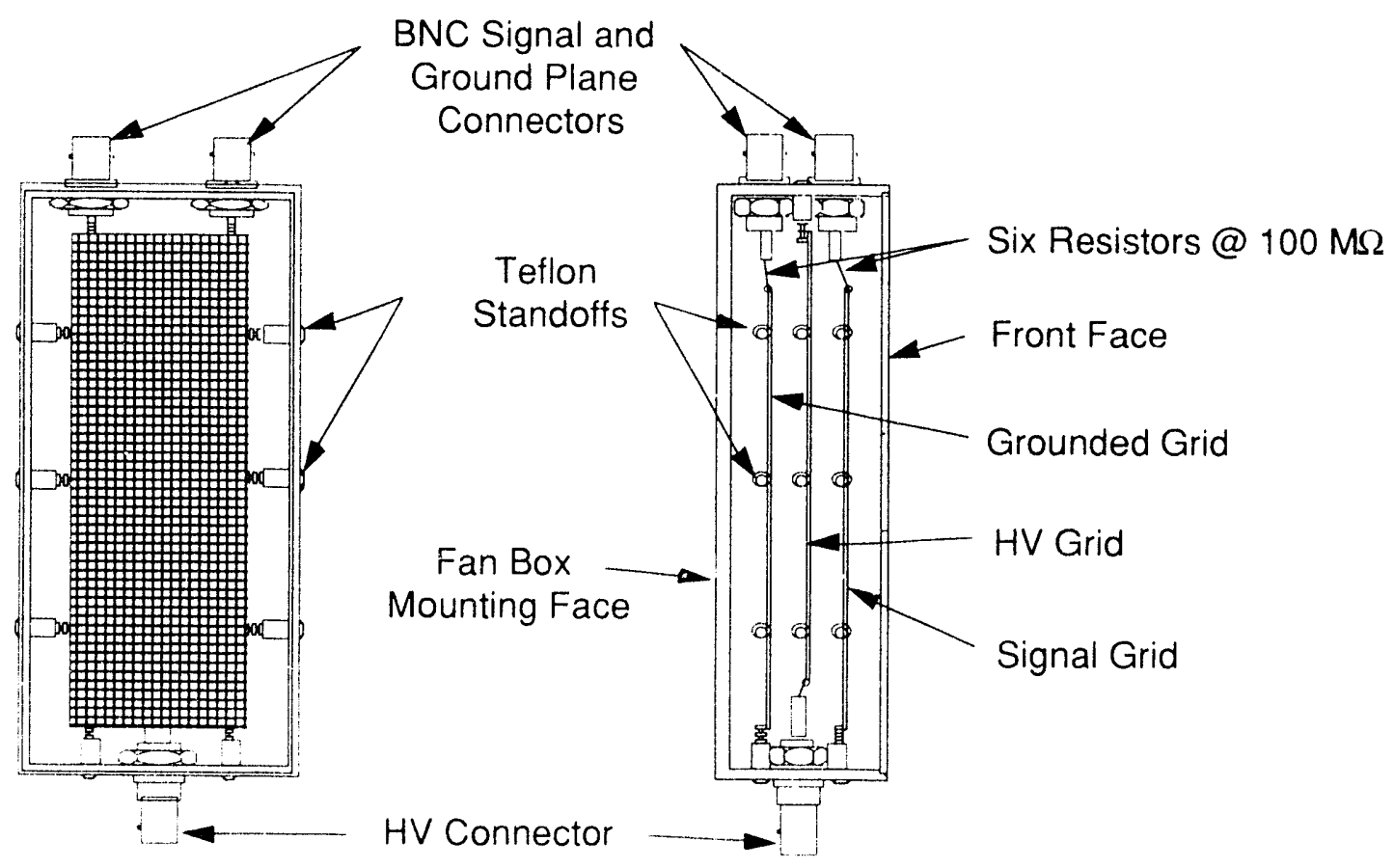

Fig. 6. Detailed firont and side view's of the ion detertor. 
final result. Grolinding the third grid improved the detector's signal-to-noise ratio; and all subsequent data were taken with the third grid grounded. The HV grid is mounted between the signal and ground grids with a $7 / 16$ in. spacing between adjacent grids. Six $100-\mathrm{M} \Omega$ resistors are soldered in series between both the signal and ground planes and their respective $\mathrm{BNC}$ connectors. These resistors limit the error currents resulting from noise voltages picked up on the signal grid while passing the signal current with a small loss. An SHV chassis bulkhead connector and two BNC chassis bulkhead connectors mounted on opposite sides of the box allow external access to all three grirls.

The air inlet (Fig. 7) is formed from a 7 -in.-long aluminum tube, with a $1-3 / 8$ in. i.d., velded to a $1 / 4$-in.-thick aluminum flange. The tube is welded into a 1.5 -in. hole that is cut into the center of the 2-in. by 2-in. flange. Four clearance holes for 4-40 screws are drilled and counter sunk $90^{\circ}$ apart on a 1.75 -in. bolt circle for mounting on the front of the ion detector box. The air inlet serves to transport air from the sample enclosure and, more importantly, to ensure that no alpha particles can reach the ion detector. The length of the air inlet is not critical; lengths from 0 in. to $8 \mathrm{ft}$. have been used with this detector (see Sec. 4.5).

\subsection{LRAD System}

A simple LRAD-based sample monitor is shown in Fig. 8: The LRAD and fan (described in detail in Sec. 3.1) are on the left side; the sample chamber (right side) is an aluminum box measuring $9 \mathrm{in}$. by 6 in. by 5 in. The LRAD is connected to the sample chamber by a section of aluminum pipe that prevents alpha particles from directly entering the detector. The section of aluminum pipe mounted on the input side of the sample enclosure is an ion filter that is shown in detail in Fig. 9. A heavy wire runs between two SHV connectors axially down the center of the aluminum pipe. All of the data for this report was taken with $+2000 \mathrm{~V}$ applied to the central wire. In most cases the filter is superfluous, but in the presence of large ion concentrations, the filter is required to maintain good sensitivity. An external background of $12000 \mathrm{fA}$ (with the filter off) is reduced to the standard $(\leq 10 \mathrm{fA}$ ) when the filter is turned on. We made no attempt to optimize the filter voltage once we realized that $2000 \mathrm{~V}$ were sufficient. The HV power supply (HVPS) that provides the $2000 \mathrm{~V}$ also makes an extra ground connection, which must be considered for optimum noise performance. Only one of the SHV cunnectors is required for the $\mathrm{HV}$ connection; the other is simply used as a convenient-length standoff.

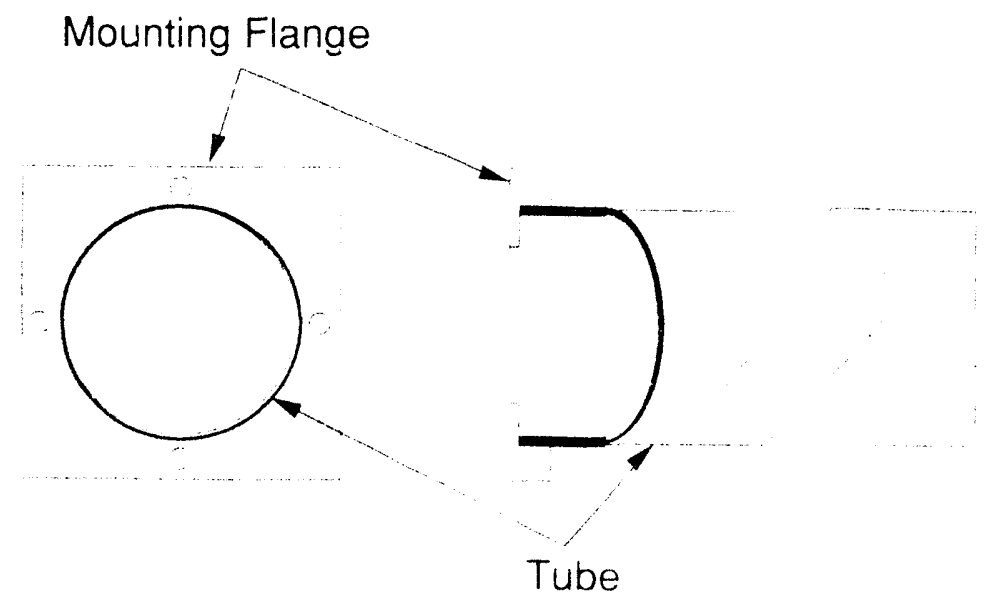

Fig. 7. Front and crossisesetion views of the air inlet. 


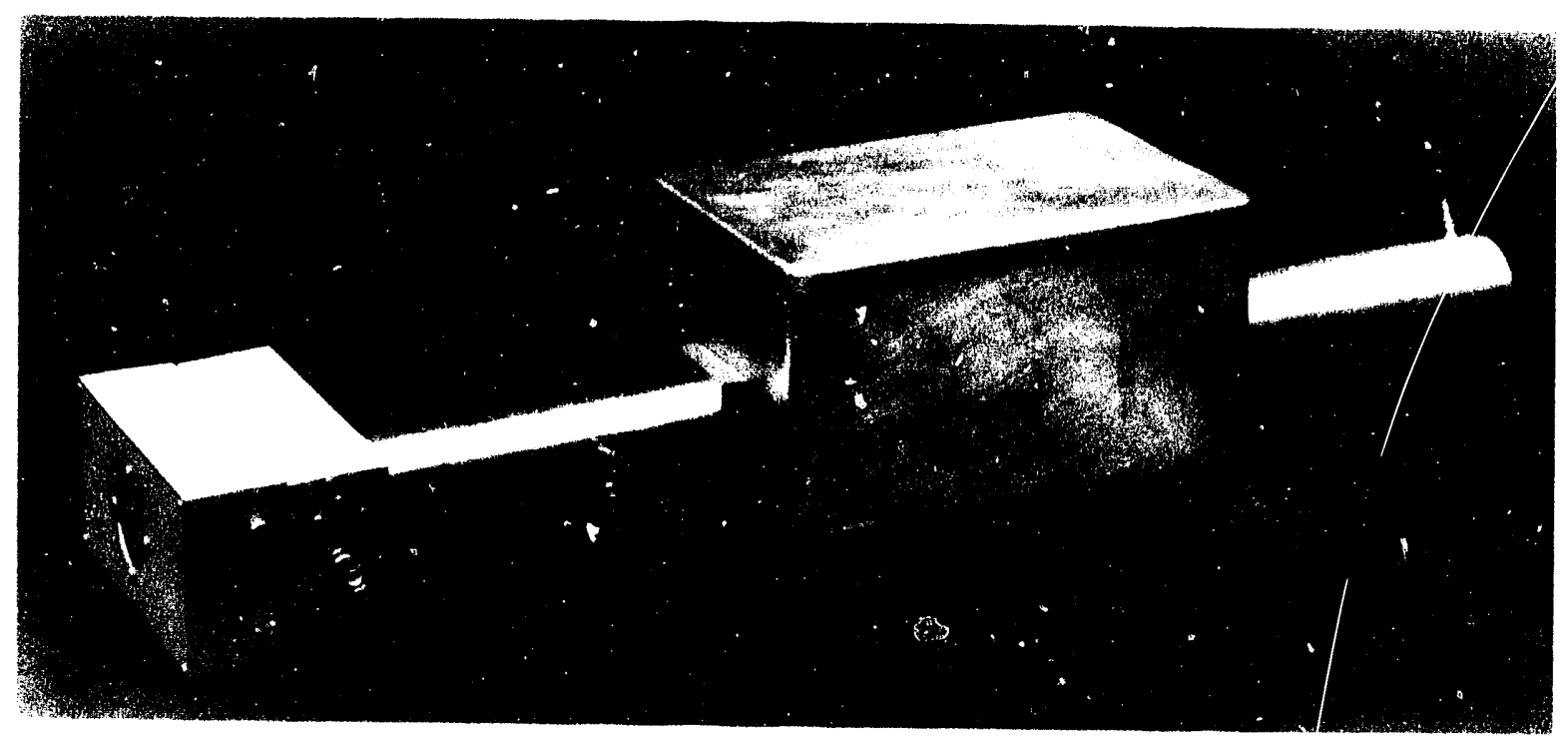

Fig. 8. Prototype LRAD detector and sample chamber

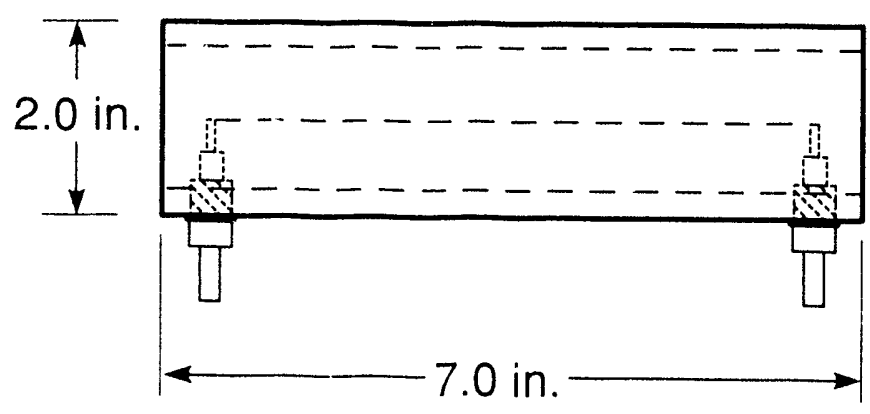

Fig. 9. Ion filter used on LRAD system.

Figure 10 illustrates the entire prototype LRAD monitor system. The LRAD, sample enclosure, and ion filter are shown in detail in Fig. 8; these assemblies are described in detail in the previous paragraphs and in Sec. 3.1. As mentioned previously, a 2000-V HVPS drives the ion filter, while the LRAD is powered by a $300-\mathrm{V}$ battery. Power for the fan is provided by a simple 12 -Vdc power supply (not shown); the fan is electrically isolated from the ion detector, so the quality of the fan power supply is not critical. The output from the ion chamber is connected directly to the electrometer input; this connection is very sensitive to noise, so it should be as short as possible. At this time, our ion chamber is connected to the electrometer by a BNC adaptor with no cable at all. The Keithley 617 electrometer can be controlled over an IEEE bus; and a Macintosh computer, which runs the LabView data acquisition program (detailed in Sec. 3.3), controls the electrometer and performs averaging and some statistical analysis of incoming data prior to display. 


\subsection{Data Acquisition System}

3.3.1. Hardware.* Figure 11 shows the computerized data acquisition system. The electrometer is a Keithley 617 with built-in IEEE interface; the computer is a Macintosh II with a NuBus National Instruments IEEE controller board running a LabView data acquisition program described below. The controller card plugs directly into the Macintosh, and the IEEE cable connects directly to both the controller and the electrometer. All electrometer control functions are performed by the computer so access to the electrometer is not required.

3.3.2. Software. A block diagram of the acquisition program is presented as Fig. 12 . The complete program is available but we have chosen not to include it in this presentation. Figure 13 is an example of the computer output for a typical data run (background in this case). The numbers in parens in the text description refer to the features pictured in Fig. 13.

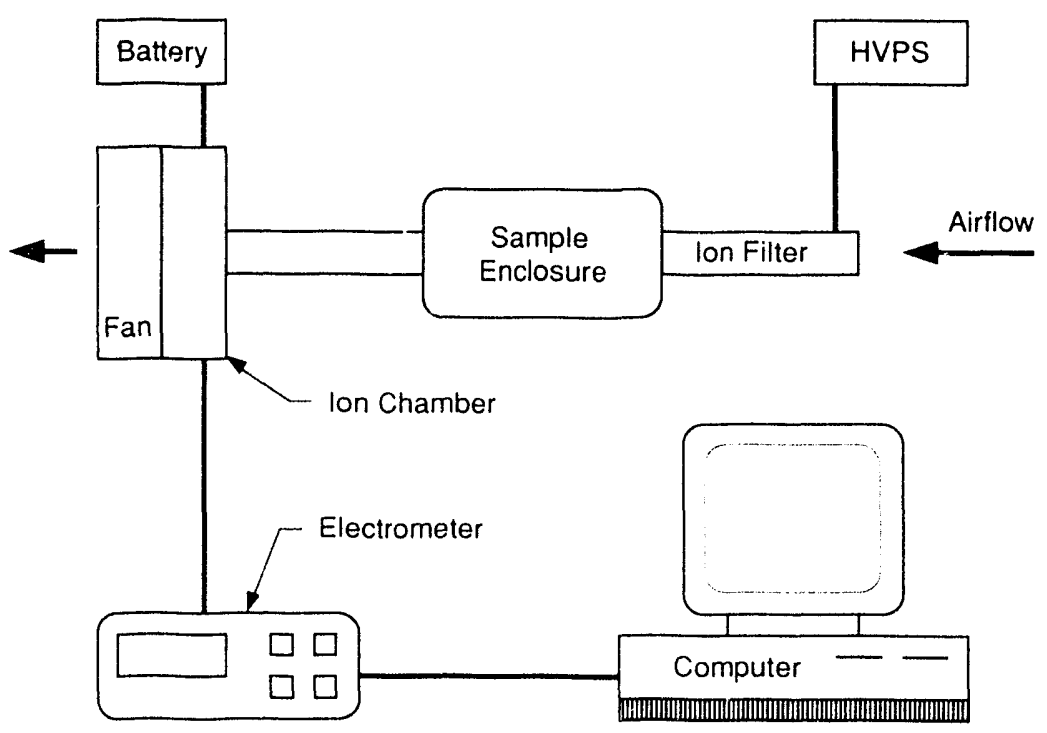

Fig. 10. Prototype LRAD monitor system.

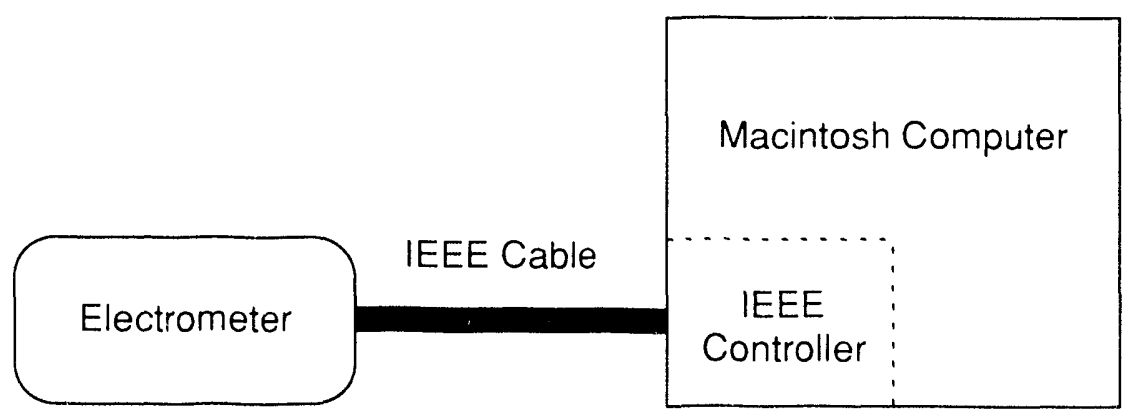

Fig. 11. Hardware configuration for the data acquisition system.

* In the foliowing description, the use of brand names is meant to convey information on the setup used and is not to be taken as an endorsement of the products by the authors or by Los Alamos National Laboratory. 


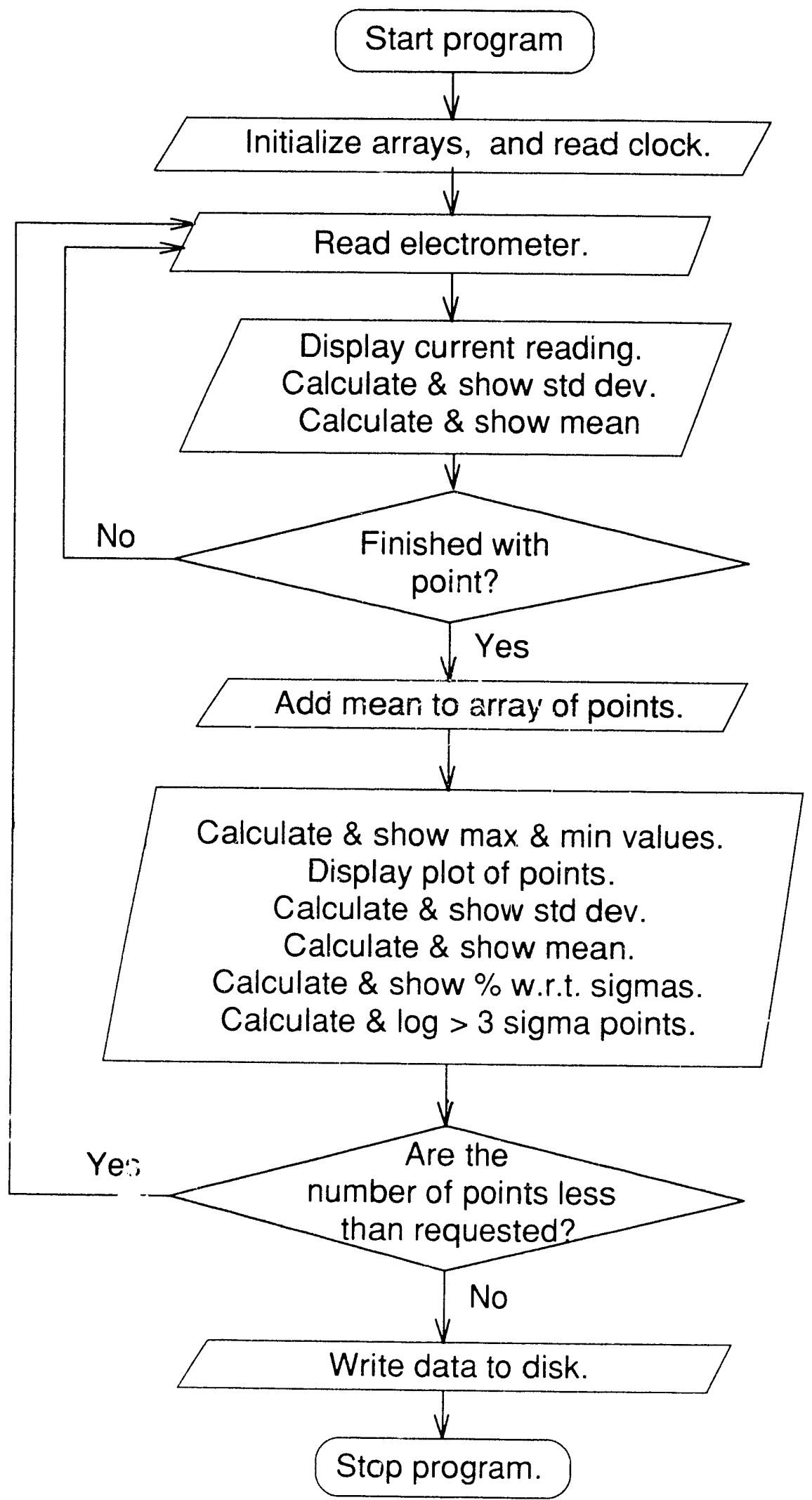

Fig. 12. Block diagram of data acquisition program. 


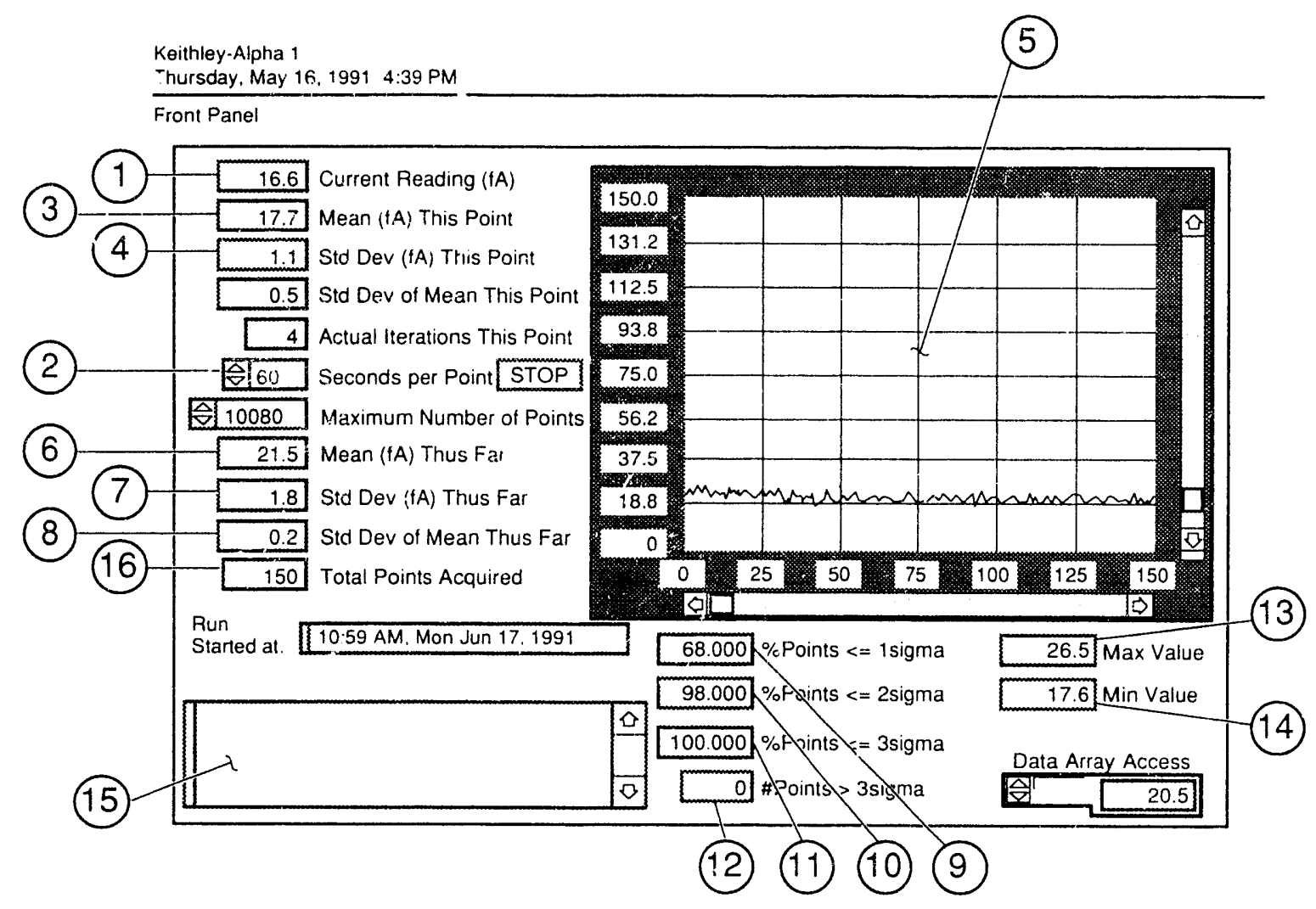

Fig. 13. Front panel display of computer data acquisition system.

When the data acquisition and display program first runs, the computer initializes the electrometer to monitor the detector current and to transmit each measurement to the computer. The computer continuously reads and displays (1) the digitized meter output. After each minute [variable (2)] the computer determines the mean value (3) and the standard deviation (4) of the readings for that minute. The mean value is plotted on the screen in a strip chart fashion (5). Each successive minute's worth of data is acquired in similar fashion. As the mean values are acquired, an overall mean (6), standard deviation (7), and standard deviation of the mean (8) are calculated for all of the plotted data. This is a smoothing procedure intended to give an accurate average value of the current. At the end of a data run, determined by either reaching the maximum number of points or by a manual stop command, the one-minute data averages may be written to disk if desired. As an indication of the statistical significance of the plotted distribution, the percentage of points within one (9), two (10), and three (11) standard deviations are indicated, as well as the number of points lying outside three standard deviations (12) and the maximum (13) and minimum (14) values. In the event of noise bursts, the number of points outside 3 std dev can be noticeably large; each value outside $3 \mathrm{std}$ dev is listed (15) to aid in tracking down the cause of the excursion. The total number of time intervals recorded is also displayed (16). The one-minute averaging is the default setting, but the averaging time can be set (2) to any value greater than about $1 \mathrm{~s}$, the time it takes the meter to generate a new reading. 


\section{RESULTS}

Every set of data is recorded by the computer both as a front panel display (as in Fig. 13) and as a set of numbers corresponding to the averaged data that are recorded on a hard disk for further analysis.

\subsection{Source Responses and Sensitivity}

The graph in Fig. 14 shows the response of the LRAD to two small ${ }^{239} \mathrm{Pu}$ sources. The figure illustrates about $20 \mathrm{~min}$ of background, $20 \mathrm{~min}$ with a 1000 -dpm source in the sample enclosure, 20 min of background, 20 min with a 400 -dpm source in the chamber, and a final 20 min of background.

Both sources are easily differentiated from the background noise and, therefore, do not provide a true measure of the sensitivity of the prototype. The sensitivity is extrapolated from the numerical results:

$$
\begin{array}{ll}
\text { Response }(1000 \mathrm{dpm}) & =71.3 \pm 2.4 \mathrm{fA}, \text { and } \\
\text { Background } & =9.3 \pm 1.2 \mathrm{fA} \\
\text { Detector Sensitivity } & =0.063 \pm 0.003 \mathrm{fA} / \mathrm{dpm} .
\end{array}
$$

The detector sensitivity depends strongly on the airflow through the LRAD so the same LRAD may give slightly different results at different times.

If a simple threshold is set between the signal level and the noise, the detection efficiency and false-alarm rate can be calculated as shown in Fig. 15. If the noise is approximately gaussian, the detection efficiency and false-alarm rate can be expressed as a function of standard deviation $(\sigma)$ as shown in Table I. The probabilities for intermediate values are thoroughly tabulated5; Table I is simply a truncated version of such tables. The number of standard deviations the detection threshold is away from the background and signal indicates the false-alarm and detection rates, respectively. If the false-alarm rate is set at $2.3 \%$ (corresponding to $2 \mathrm{~s}$ ) and the detection probability is set at $99.85 \%$ (corresponding to $3 \sigma$ ), then the detection threshold is given by

$$
\begin{aligned}
\text { Detection Threshold } & =2 \sigma_{\text {noise }}+3 \sigma_{\text {signal }} \\
& =9.6 \mathrm{fA} \\
& \propto 150 \mathrm{dpm} .
\end{aligned}
$$

Table I. Probability of random events.

\begin{tabular}{|c|c|c|}
\hline $\begin{array}{c}\text { Separation of Threshold } \\
\text { from Noise or Signal }\end{array}$ & $\begin{array}{c}\text { Detection } \\
\text { Efficiency (\%) }\end{array}$ & $\begin{array}{c}\text { False-Alarm } \\
\text { Rate (\%) }\end{array}$ \\
\hline $1 \sigma$ & 84.0 & 16.0 \\
$2 \sigma$ & 97.7 & 2.30 \\
$3 \sigma$ & 99.85 & 0.15 \\
$4 \sigma$ & 99.997 & 0.003 \\
\hline
\end{tabular}




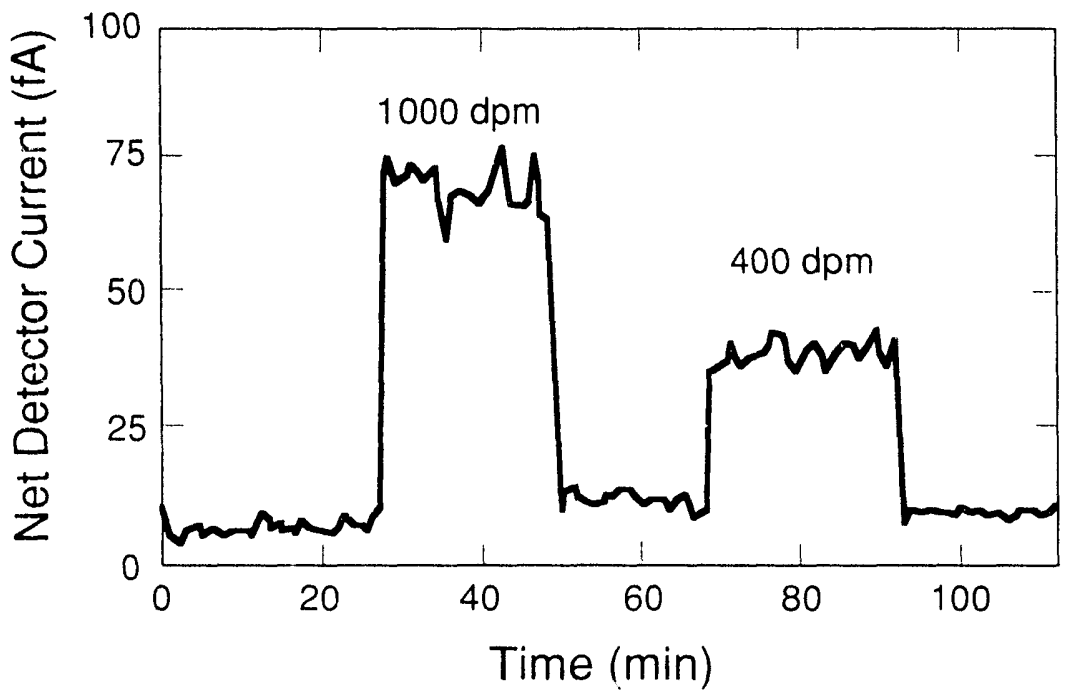

Fig. 14. Response of prototype LRAD to two small ${ }^{234} \mathrm{Pu}$ sources.

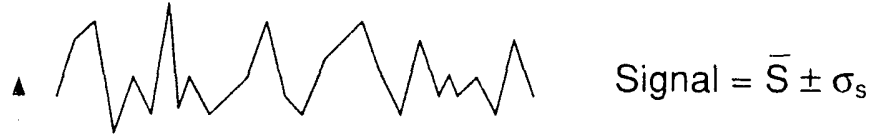

Detection efficiency $=d \sigma_{\mathrm{s}}$

】

Threshold

False-alarm rate $=f \sigma_{n}$

Fig. 15. Detection efficiency and false alarm rate as a function of threshold setting.

\subsection{Detector Linearity}

The mean response and standard deviation were calculated for each source response shown in Fig. 14. Similar means and standard deviations were calculated for two intermediate sources (not shown). Since the LRAD responds to the number of ions detected and lower energy alpha particles generate fewer ions, different types of sources will generate different LRAD responses. For comparison, all responses were normalized to ${ }^{239} \mathrm{Pu}(5.14 \mathrm{MeV})$; the resulting plot of net detector current as a function of source strength is presented in Fig. 16. A large dc offset was inherent in these measurements and was subtracted before plotting.

\subsection{Noise Sources}

Three types of noise must be considered in interpreting the LRAD results. Spike (or transient), dc (or very low-frequency), and ac (or high-frequency) noise contribute to errors in LRAD measurements. The noise contributions are divided into three regimes by 


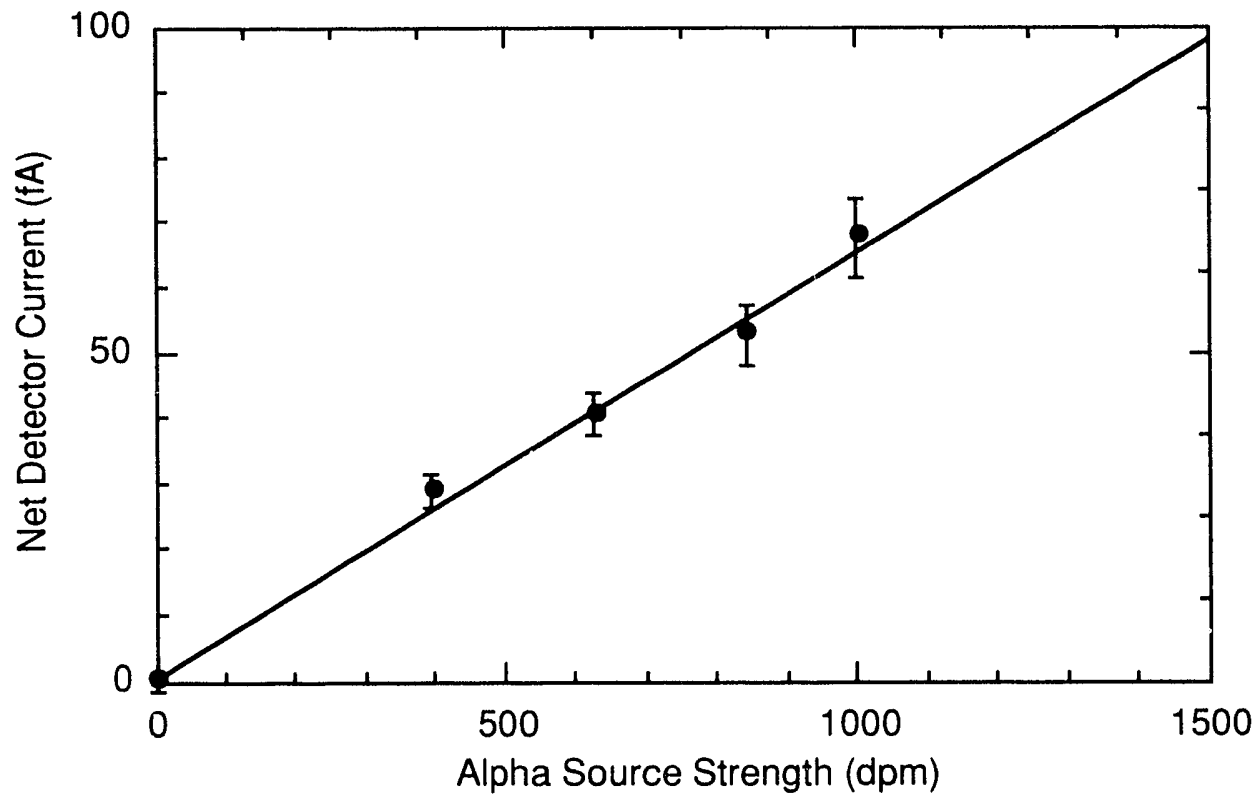

Fig. 16. Linearity of detector response as a function of source strength.

the averaging time. The dc noise component has a much longer period than the averaging time and is often considered a dc offset or slow dc drift. The ac noise componert has a periou comparable to the averaging time and is responsible for the "hash" on any given measurement. Finally, noise that is much faster than the averaging period is completely averaged away and does not affect the data unless it is la 'e enough to skew an entire averaged data point. These anomalies are referred to as noise spikes.

4.3.1. Potential de noise sources and solutions. The most obvious dc offset is created by the HV applied to the HV grid. This voltage will cause a small leakage current to flow; if any of the leakage current passes through the signal grid, it will induce a small offset in the measured signal. Leakage current effects can be reduced in two ways: (1) reducing the HV applied to the LRAD will reduce the leakage; and (2) mounting the signal and HV grids separately on a grounded surface as shown in Fig. 17b reduces the effect of the leakage current on the signal grid. Figure 17 illustrates both common insulator (Fig. 17a) and separate insulator (Fig. 17b) mounting techniques. With a common insulator, leakage current from the HV grid passes through the signal grid; while with separate insulators, the leakage current does not pass through the signal grid.

Radon background in the measuring room can also create a slowly varying offset in the measurements. Radon that decays after entering the sample enclosure will not be removed by the ion filter; thus, alpha particles produced in these decays will create a relatively constant background. This sensitivity to radon is critical for the radon detector application discussed in Sec.5.2, but in other applications the radon creates a background, rather than an interesting measurement. Cosmic rays passing through the sample enclosure also leave ionization trails as they travel. The sensitivity to both cosmic rays and radon scales directly with the sample enclosure volume; thus, these backgrounds can be largely ignored in small enclosures.

Both piezoelectric effects (in the cable's dielectric) and triboelectric effects (from friction between the shield and the dielectric) can cause measurable low-frequency currents if the coaxial cable between the detector and the electrometer is disturbed. The 


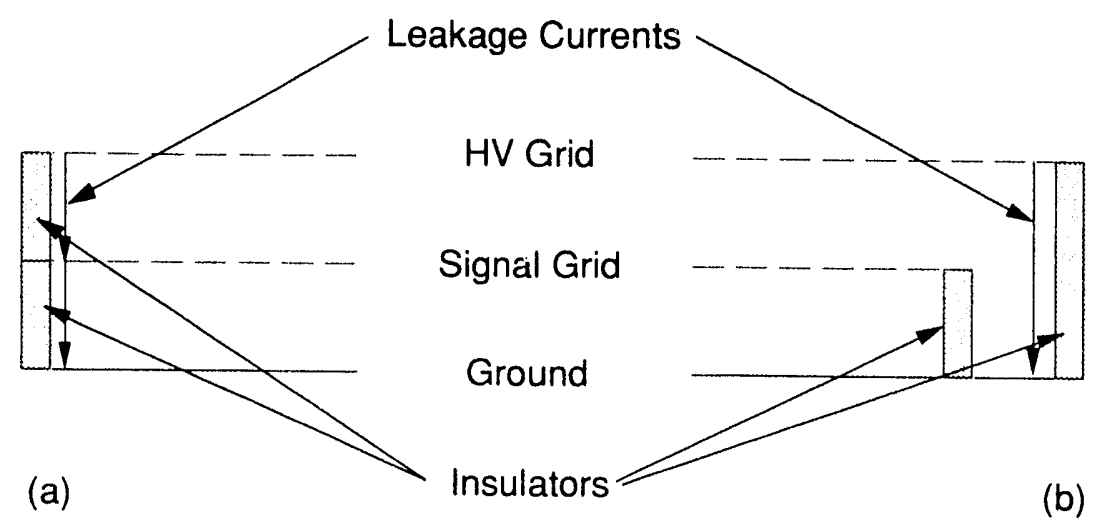

Fig. 17. Leakage currents in unguarded (a) and guarded (b) two-grid detectors.

recommended solutions include tying the cable down and using special low-friction cables. In our experience, using a very short cable (or a BNC adaptor) to make this connection is the best method.

Comparing a signal with a background measurement taken immediately before the signal is a universal method for eliminating low-frequency noise and drifts. This type of measurement will be programmed into the final LRAD software so that the system is measuring background whenever there is no potential signal present.

4.3.2. Potential ac noise sources and solutions. An unavoidable component of ac noise in LRAD detectors is caused by statistical variations in the signal itself. If the averaging time is predefined as $t$ minutes, every source of strength $\mathrm{s} d p m$ will have a signal proportional to st/2 with an intrinsic statistical uncertainty s given by $\sigma=\sqrt{t \mathrm{~s} / 2}$. This noise is simply $\sqrt{\mathrm{N}}$ statistical noise, where $\mathrm{N}$ is the total number of counts. The limitation for a detection efficiency given by n $\sigma$ (see Table I) can be determined from the relationship st $/ 2=n \sqrt{s t / 2}$ or $s=2 n^{2} / t$. For example, if $n=3$ (corresponding to $99.85 \%$ detection efficiency) and $\mathrm{t}=0.1 \mathrm{~min}$, then the smallest source that can be observed is $180 \mathrm{dpm}$. This is a fundamental limit independent of detection technology.

HV breakdown in the LRAD can cause a component of ac noise that is random due to the many small discharges in the detector. This noise component is reduced by operating the ion detector at as low a voltage as possible. Larger alpha sources generate more air ions that, in turn, generate a space charge around the signal grid. Thus, larger HVPSs are required to efficiently detect large alpha sources. In our experiments, the $300-\mathrm{V}$ HV was required to efficiently detect the ions from a 240000 -dpm source, but $100 \mathrm{~V}$ were sufficient to collect all ions from a 1000-dpm source. Thus, LRADs that are optimized for high sensitivity have a lower HV noise contribution.

Externally generated electronic ac noise can enter the LRAD system through a number of paths including (1) the HVPS wiring, (2) rf pickup in the LRAD wiring, (3) rf pickup in the LRAD-to-electrometer connection, and (4) ground loops in the LRAD system. External noise sources, noise pickup, and ground loops are covered in detail in other reports. ${ }^{4}$ These noise sources have been controlled by (1) reducing the HVPS to a $300-\mathrm{V}$ battery and a short cable, (2) shielding the LRAD with a well-grounded enclosure, (3) shortening the connecting cable as much as possible, and (4) reducing the number of ground connections to the LRAD system. 
4.3.3. Transient noise (noise spikes). If the HV discharges within the LRAD, transient noise spikes can be created if the discharges are large and intermittent. Often such a discharge is initiated by physical disturbance of the detector or by a foreign particle (such as dust) enterng the detection region. Many transient HV discharges can be avoided by eliminating physical disturbance of the ion detector or HV cable and by filtering incoming air for the detector. As in the case of ac noise, lowering the HV will reduce the frequency and severity of $\mathrm{HV}$ discharges.

As with ac noise, externally generated transient noise can enter the LRAD system through a number of paths, including (1) the HVPS wiring, (2) rf pickup in the LRAD wiring, (3) rf pickup in the LRAD-to-electrometer connection, and (4) ground loops in the LRAD system. The proposed solutions are much the same as those listed in Sec. 4.3.2, with one addition. Transient noise sources are often much stronger than the other types so it is often worthwhile to physically move the LRAD away from the noise source. Transient noise sources and solutions are also discussed in Ref. 4.

\subsection{Detection Gas}

Although the LRAD uses ambient air as a detection medium, all tests have been performed in Los Alamos; therefore, it might be possible that something "magical" is in the Los Alamos environment which allows the LRAD to operate effectively. It has also been suggested that dust particles in the ambient air might be the ion transfer medium. To test both of these hypotheses, we used three different gas mixtures (ambient air; dry, filtered air; and dry, filtered nitrogen) and operated the LRAD with both positive and negative HV applied. The results of these tests are summarized in Fig. 18, which includes the detector response to a 1000-dpm alpha source as well as a background measurement in each configuration. The dry nitrogen signal $(+\mathrm{V})$ source response might be a bit larger than the others, and the dry nitrogen (-V) background might be a bit low, but otherwise all responses are remarkably similar. This indicates that neither gas composition, airborne dust concentration, water content, nor HV polarity has a significant effect on LRAD operation. The small variations observed are being studied more carefully in a new experiment.

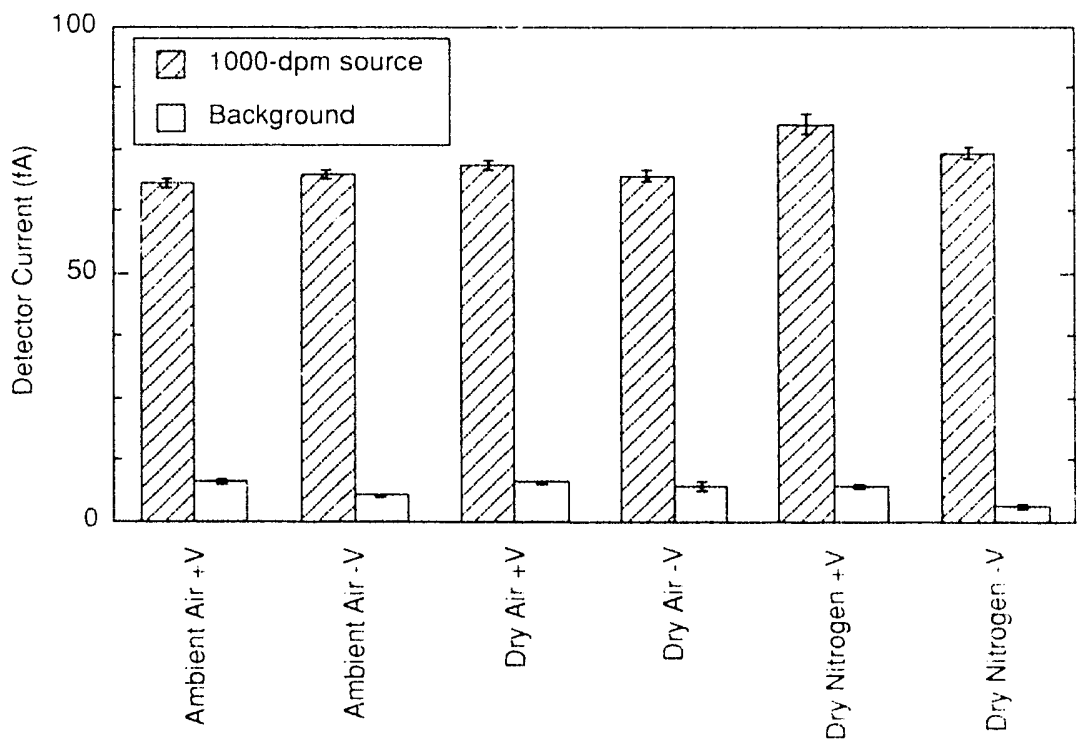

Fig. 18. Response of the LRAD detector operating with differenth gas mivtures and $/ I$ polarities. 


\subsection{Ion Lifetime}

We have re-analyzed the ion lifetime data presented in Ref. 3 and present some additional insights. An 8-ft-long aluminum pipe with an i.d. of $1-3 / 8$ in. was attached to the front of the ion detector. The airtlow in the pipe was measured at $190 \mathrm{ft} / \mathrm{min}$, corresponding to about $2.5 \mathrm{~s}$ for ions to move the length of the pipe. The $240000 \mathrm{dpm}$ alpha source was positioned at 1 -ft intervals along the pipe, and the detector current was measured in each case. Although the raw data presented in Fig. 19 are the same as those in Ref. 3 , in this case the data are fitted with a $1 / t$ fit of the form $N=N_{0} /\left(\rho t N_{0}+1\right)$, where $N$ is the number of ions at time $t, N_{0}$ is the number of ions initially, and $r$ is the recombination coefficient. ${ }^{6}$ The results of the fit are $\mathrm{N}_{0}$ (experiment) $=0.8 \times 10^{5} \mathrm{ions} / \mathrm{cm}^{3}$ and $\rho($ experiment $)=2.4 \times 10^{-6} \mathrm{~cm}^{3} / \mathrm{s}$. A calculation of $\mathrm{N}_{0}$ from the source strength gives $\mathrm{N}_{0}$ (theory) $=3.3 \times 10^{5}$ ions $/ \mathrm{cm}^{3}$, and the tabulated value for $\rho$ in free air 6 is $\rho$ (theory) $=$ $1.4 \times 10^{-6} \mathrm{~cm}^{3} / \mathrm{s}$.

Many of the measurements used in calculating the experimental results are only good to about $50 \%$. Furthermore, this analysis assumes that all ions generated by the alpha source are involved in the volume recombination process (that is calculated), whereas many are going to recombine in a columnar fashion (not calculated). ${ }^{1}$ Therefore, it is quite reasonable that $\mathrm{N}_{0}$ (experimental) be significantly smaller than $\mathrm{N}_{0}$ (theory). Also the recombination coefficient $\rho$ in free air is probably not the same as $\rho$ in an aluminum pipe. With these caveats, the agreement between the measured and predicted values seems quite good. This experiment is also being repeated.

For the first "half-life," the correct $1 / \mathrm{t}$ decay shown in Fig. 19 is similar to the $\mathrm{e}^{-1}$ fit generated in Ref. 3 ; thus the lifetime reported previously $(4.6 \pm 1 \mathrm{~s})$ agrees well with the lifetime calculated from Fig. 19, using $\tau \equiv 1 /\left(\rho N_{0}\right)=5.2 \pm 2 \mathrm{~s}$. Both of these values agree quantitatively with the theoretical calculation of $\tau=2.2 \mathrm{~s}$.

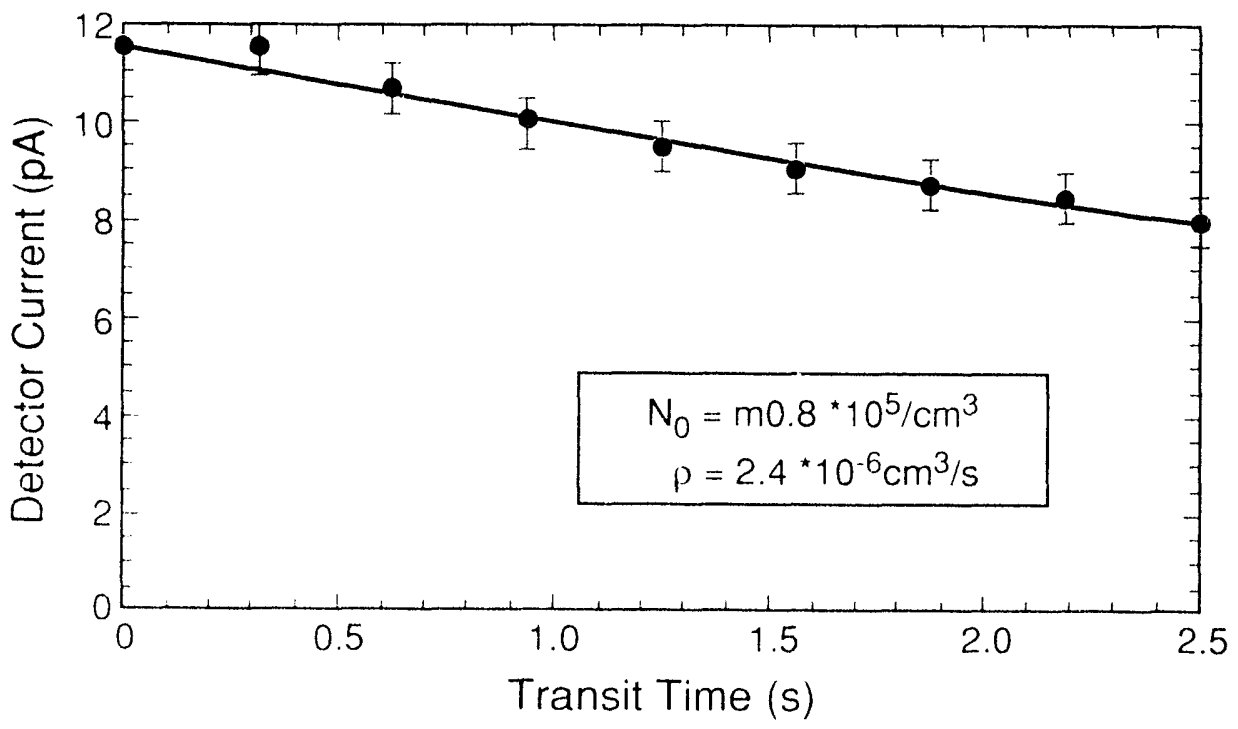

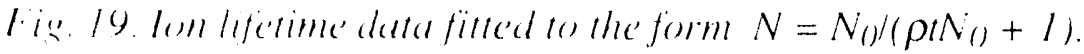




\section{APPLICATIONS}

As mentioned in the introduction, the LRAD alpha detection system has many advantages over traditional alpha detectors. Many of these advantages translate directly into applications that were expensive, difficult, or impossible to achieve with the older technology.

\subsection{LRAD Advantages}

Alpha contamination monitors based on the LRAD technique have at least four significant advantages over traditional alpha monitors.

1. Sensitivity - The LRAD alpha detector is 10 to 100 times more sensitive than traditional alpha detectors. As illustrated in Fig. 20, at high source strengths both traditional detectors and LRAD detectors are essentially $100 \%$ efficient. With very small amounts of contamination, the LRAD is much more likely than conventional detectors to detect the radiation. This improved sensitivity is essential in meeting new DOE guidelines for contamination limits.?

2. Surface Area - The LRAD monitor can monitor all emissions from a large surface simultaneously, rather than only a small area as is typical of traditional instruments. A large surface with a uniform low-levei contamination could never register on a traditional monitor, but the sum of all the contamination would be easily detectable by an LRAD system. Traditional alpha monitors are limited to scanning surface areas of several-hundred square centimeters at any given time, while an LRAD monitor is limited only by the size of the attached sample enclosure.

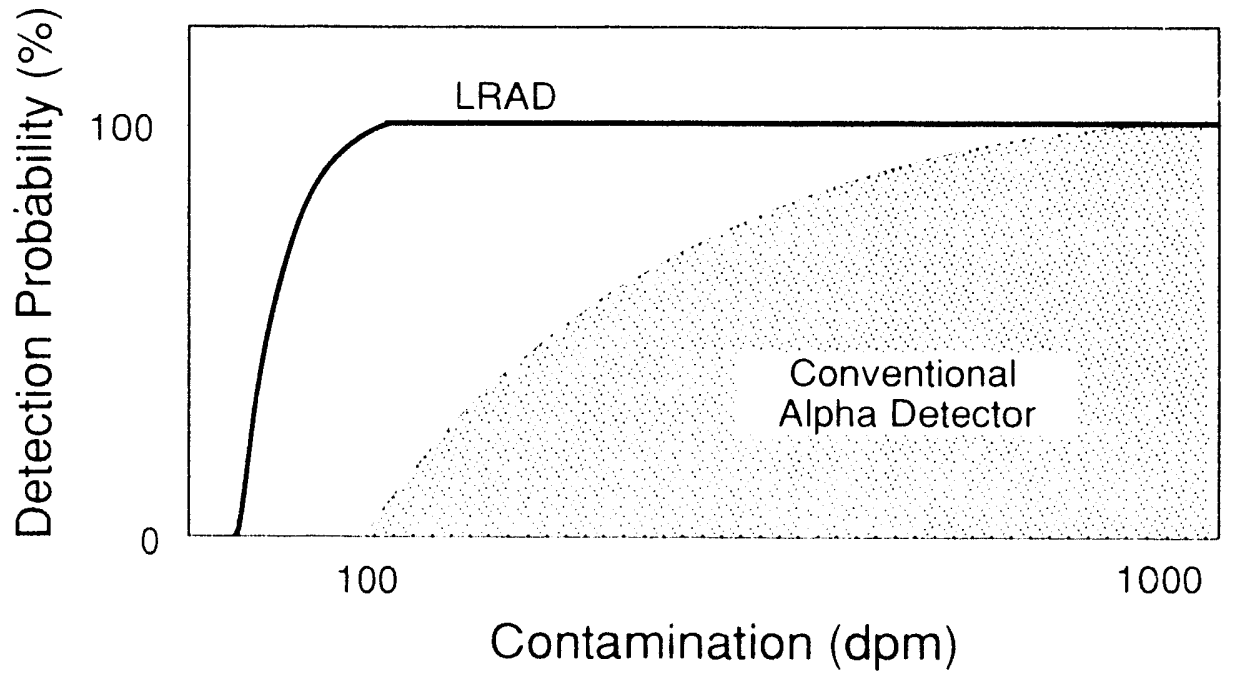

Fig. 20. Comparison of LRAD sensitivity to traditional alpha detector sensitivity for small contamination levels. Note that the scales are only approximate and details will lary depending on the configuration of the delectors. 
3. Convoluted Surfaces - Unlike traditional detectors, the LRAD is not limited by the range of alpha particles in air $(<5 \mathrm{~cm})$; if the ions can be transported from a contamination location, that cotitamination can be observed. This means that the LRAD could be used to scan inside cracks, crevices, glove fingers, electronic enclosures, and other restricted locations.

4. Automation - In an effort to overcome the surface area limitations of traditional monitors, a small alpha detector is often scanned over clothing, bodies, or equipment in an attempt to monitor all locations on that surface. The efficiency of this scan depends strongly on the skill of the individual performing the scan, the time allowed for the scan, and the characteristics of the surface being scanned. With the LRAD monitors, the suspect object (clothing, body, etc.) is placed in an enclosure for a specific period of time during which the detector either does or does not detect significant contamination. Thus, uniform monitoring is achieved, independent of personnel or surface considerations.

\subsection{Specific Potential Applications}

The four LRAD advantages discussed in Sec. 5.1 make several types of contamination monitoring much more feasible than in the past. In the following paragraphs, we present several potential applications in three groups: object monitors, personnel safety monitors, and environmental monitors.

5.2.1. Object Monitors. The small sample or source monitor illustrated in Fig. 10 is the simplest form of an object monitor, and its operation has been well documented. If the air filter, detection volume, LRAD, and fan are all enlarged (as in Fig. 21); then larger equipment and tools can be monitored. The slowly rotating turntable presents all sides of the object to the LRAD for improved sensitivity.

Currently, beeause of the difficulty of adequately monitoring such items, equipment that has been used in a contaminated area must be designated as potentially contaminated and any further use must be in controlled areas. If the equipment monitor (see Fig. 21) could be used to determine that the equipment was not contaminated, then it could be used in noncontrolled areas.

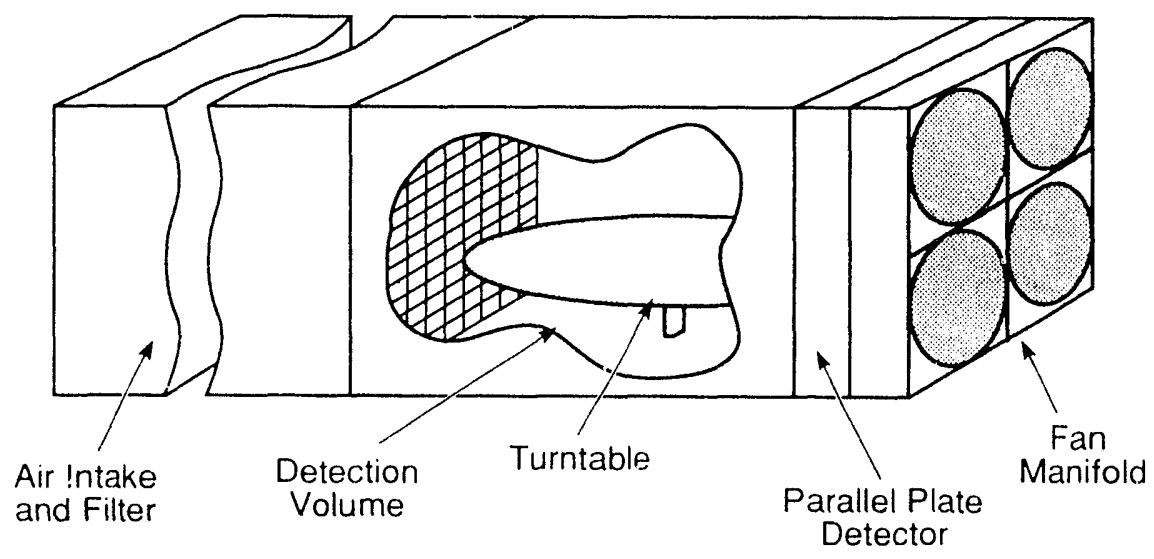

Fig. 21. Conceptual design of an equipment monitor. 
The ion detector from the equipment monitor could be altached to an enclosure with at conveyer belt to form the waste monitor illustrated in Fig. 22. In this monitor, solid waste exiting a contaminated area could be quickly and efficiently scanned to separate radioactive waste from nonradioactive waste. Presently, most waste coming from contaminated areas is treated as potentially radioactive and must be handled and stored accordingly: waste that was measured as nonradioactive by an LRAD could be disposed of through normal channels, signiiicantly reducing the quantity of "radioactive" waste generated.

Finally, if a potentially contaminated object is too large to fit in an enclosure, such as shown in Fig. 21, a portable hand-held large-equipment monitor (illustrated in Fig. 23) could be used. This device would suck air and ions into an LRAD like a small vacuum cleaner and could locate contaminated areas on large assemblies. Because both dust and nonradioactive ion sources can cause significant background in an LRAD, care would have to be used in interpreting the results of a large equipment monitor.

5.2.2. Personnel Safety Monitors. If the turntable were removed from the equipment monitor shown in Fig. 21 and if a pair of armholes with rubber seals were cut into the side of the enclosure, then the hand and arm monitor illustrated in Fig. 24 is created. Radiation workers would use this application to monitor their hands and arms for contamination before exiting a controlled area. Presently, workers have to try to monitor all of their hands and arms within an inch of a stationary detector, a difficult if not impossible feat, and many workers are inadequately monitored because of this difficulty.

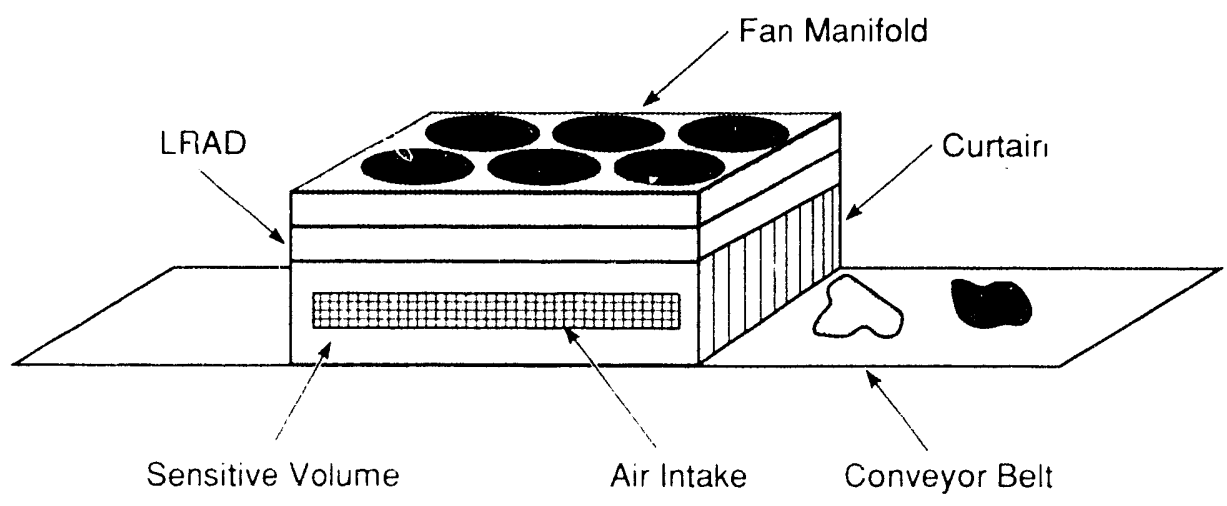

Fig. 22. Waste monitor.

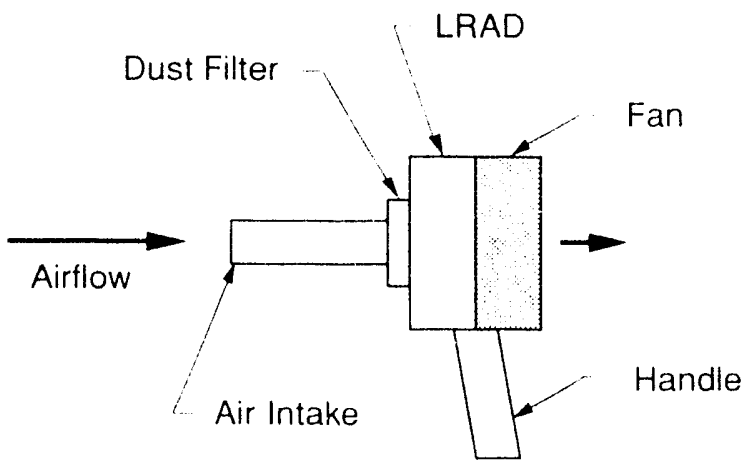

Fig. 23. Large écuipment monitor. 
Anti-contamination (anti-C) clothing wom by radiation workers is also a possible source of contamination. Following use, anti-C clothing is laundered and assumed (but not measured) to be free of radiation. Thus, "clean" anti-C garments can often destroy sensitive experimental results or trigger contamination alarms when the wearer has not been exposed to any new contamination. For many applications, new anti-C garments are specified because of the unknown properties of laundered garments. The protectiveclothing monitor shown in Fig. 25 could be used to inspect large numbers of anti-C garments and ensure that no radioactive contamination was present. Air that had flowed over the garments would be monitored for alpha-generated ions by a large LRAD attached to the enclosure.

Making the enclosure even larger results in the personnel monitor booth illustrated in Fig. 26. This booth would be large enough for a person leaving a contaminated area to step into and simultaneously monitor their hands, feet, clothing, and possessions. This application takes advantage of the breathable ambient air that is used as a detector "gas" so that a person can be enclosed in the chamber.

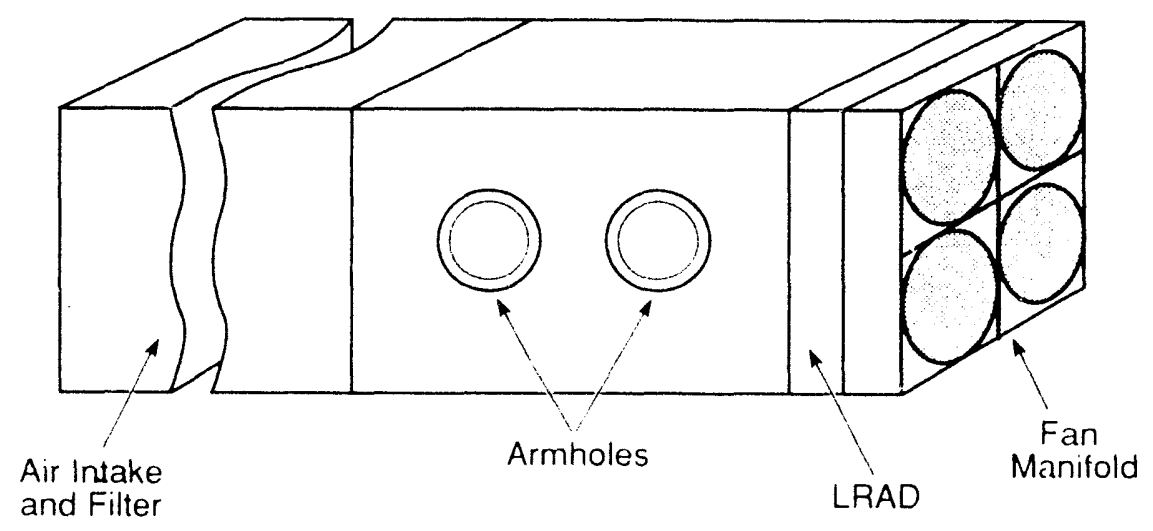

Fig. 2. Hand and arm monitur.

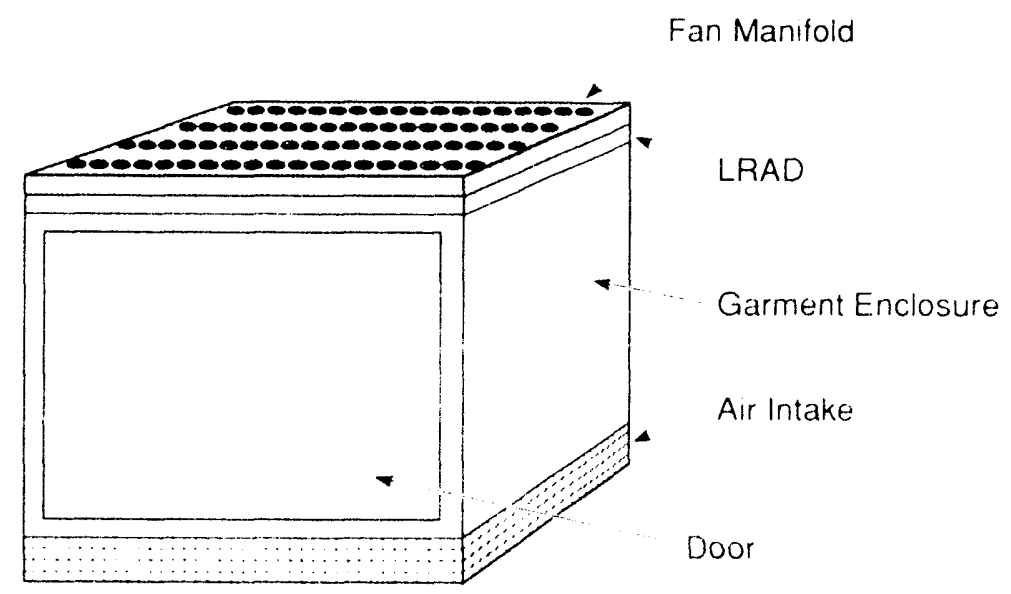

Fie. 25. Protertive dething momitor. 
5.2.3. Environmental Monitors. The simplest environmental monitor based on LRAD technology is the soil-sample monitor shown in Fig. 27. Conceptually, a soil sample is spread over the bottom of an equipment monitor, where the airflow over the soil will carry contamination-generated ions into the LRAD. A more practical version might employ a conveyer belt to continuously feed soil into the detector. Presently, soilsample monitoring is limited by the relatively small active area of traditional alpha detectors. The soil-sample monitor lakes arlvantage of the large-area monitoring potential and sensitivity of the LRAD technique.

A variation of this application is the soil-surface monitor, shown in Fig. 28, which is similar to the soil-sample monitor, except that its sensitive enclosure has no bottom. This bottomless box sits over an area of soil surface and can observe contamination on the surface without disturbing the soil. The sharp edge on the enclosure would facilitate making a good air seal against an uneven soil surface. The soil-surface monitor can observe rentamination in cracks or depressions that would be missed in the most thorough conventional survey.

Fan Manitold

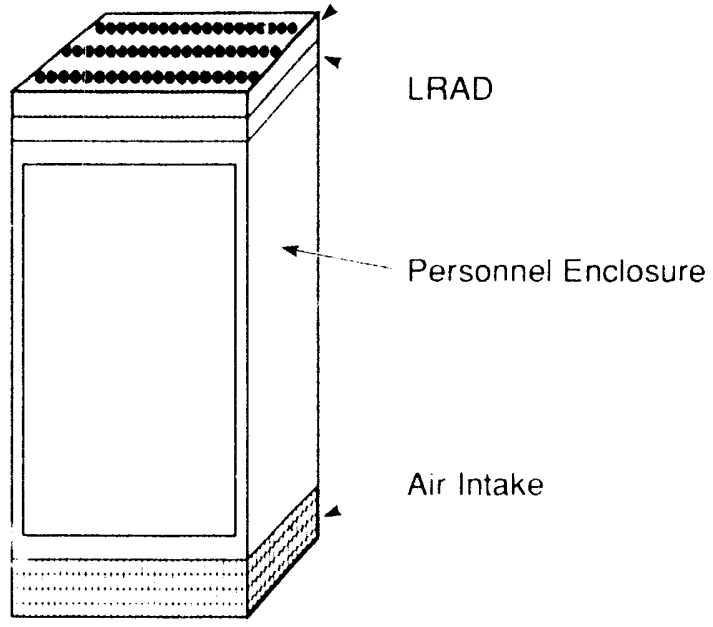

Fig. 20. Persommel monitor.

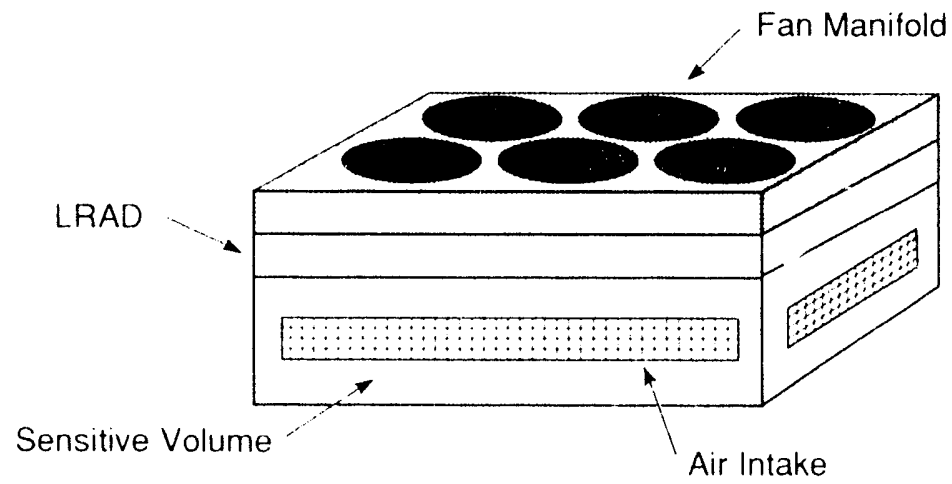

Fig. 27. Soil sample monitur. 
A more speculative soil monitor is the bulk-soil monitor illustrated in Fig. 29. In this application, a pipe is inserted into the soil, and a fan draws air through the soil and into an LRAD. This technique depends on two questionable occurrences: (1) alpha particles in soil must generate enough air ions to be observed, and (2) the ions must be carried through the soil in an airflow with little loss. We are currently testing these hypotheses.

Finally, but potentially most important, is the atmospheric radon monitor illustrated in Fig. 30. In this application, ambient air is drawn into a large decay volume through an electrostatic filter that removes any external dust or ions. Radon decays in the decayvolume-generated ions that are detected in the LRAD. The extreme sensitivity and flowthrough nature of the LRAD make it possible to monitor atmospheric radon in a minute or less, rather than the days or weeks required by conventional detectors.

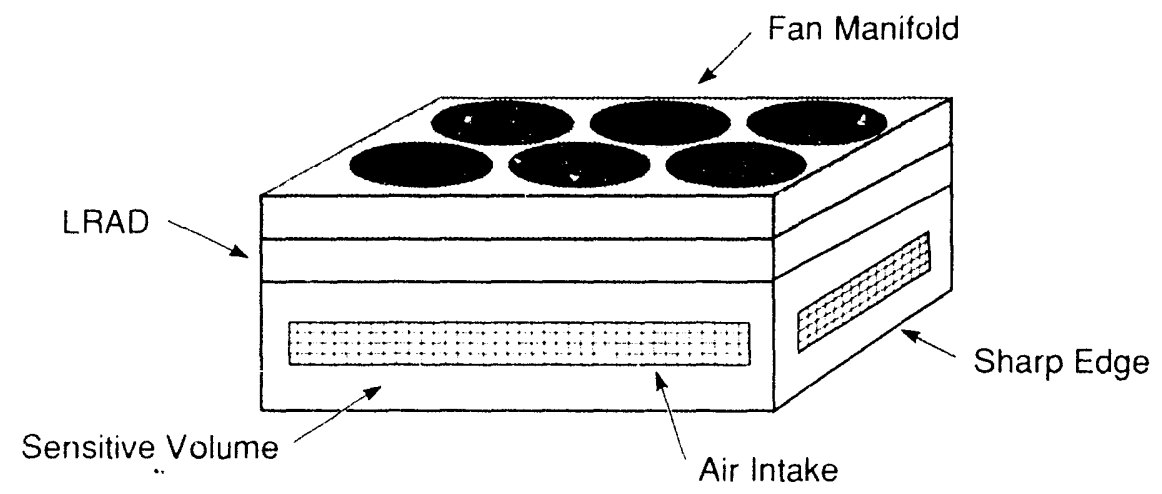

Fig. 28. Soil surfuce monitor.

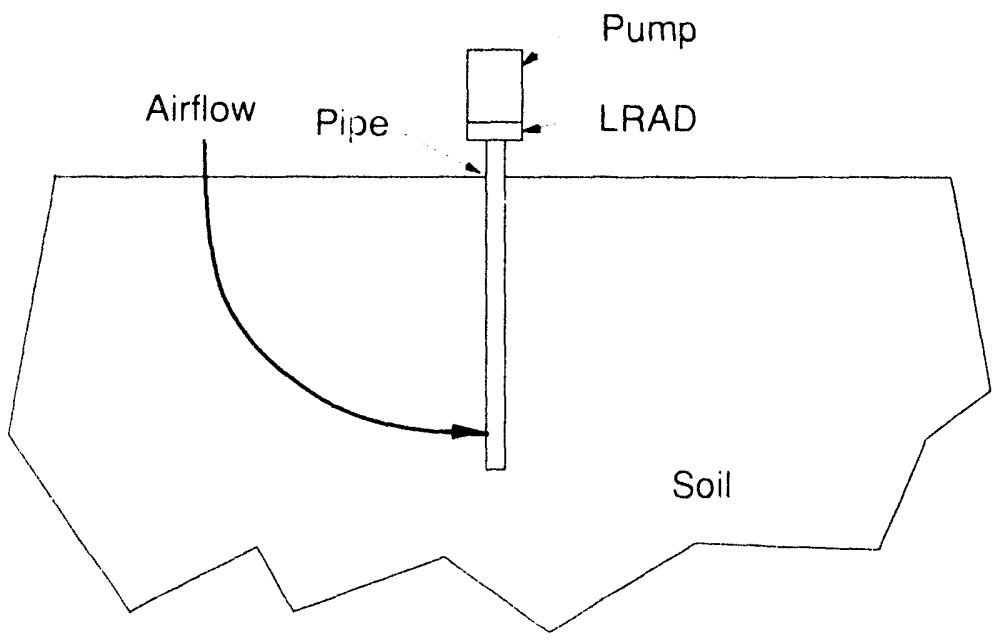

Fi.g. 29. Bulk-soil monitor. 


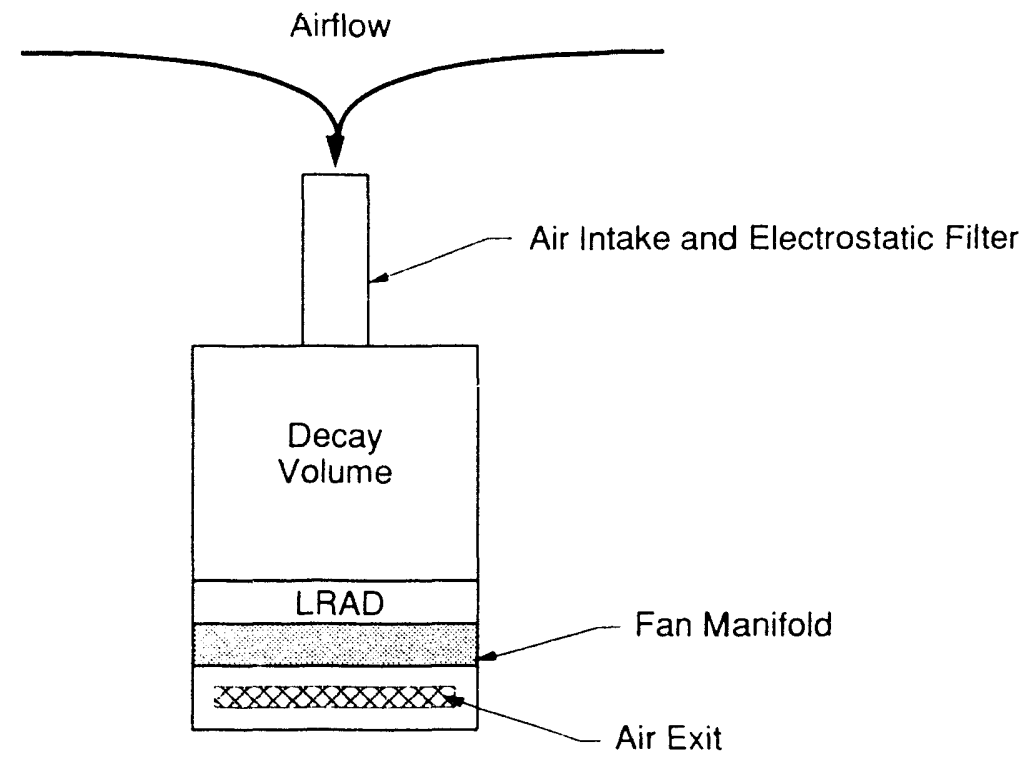

Fig. 30. Radon monitor.

\section{CONCLUSIONS}

Both this and our previous. ${ }^{3}$ report have demonstrated the usefulness of the LRAD technique for detecting alpha contamination. In this report we have presented some tests and comparisons that further validate the LRAD technique, as well as a series of potential applications that capitalize on the characteristics of the LRAD detector. Many of these applications are in the prototype stage so further results should be forthcoming

\section{REFERENCES}

1. Glenn F. Knoll, Radiation Detection and Measurement, 2nd Edition, (John Wiley \& Sons, New York, 1989).

2. L.S. Department of Energy Order 5480.11, "Radiation Protection for Occupational Workers." June 29. 1990.

3. D. W. MacArthur, "Long-Range Alpha Detector." Los Alamos National Laboratory report LA-12073-MS (1991).

4. D. W. MacArthur, "Practical Nuise Control in Electronic S. . ns," Los Alamos National Laboratory report LA-12076-MS, April 1991.

5. P. R. Bevington. Data Reduction and Error Analysis for the Physical Sciences, (McGraw-Hill, New York, 1969).

6. A. von Engle. Ionized Gases. 2nd Ed.. (Oxford Clarendon Press, Oxford, Eng and, 1965). 

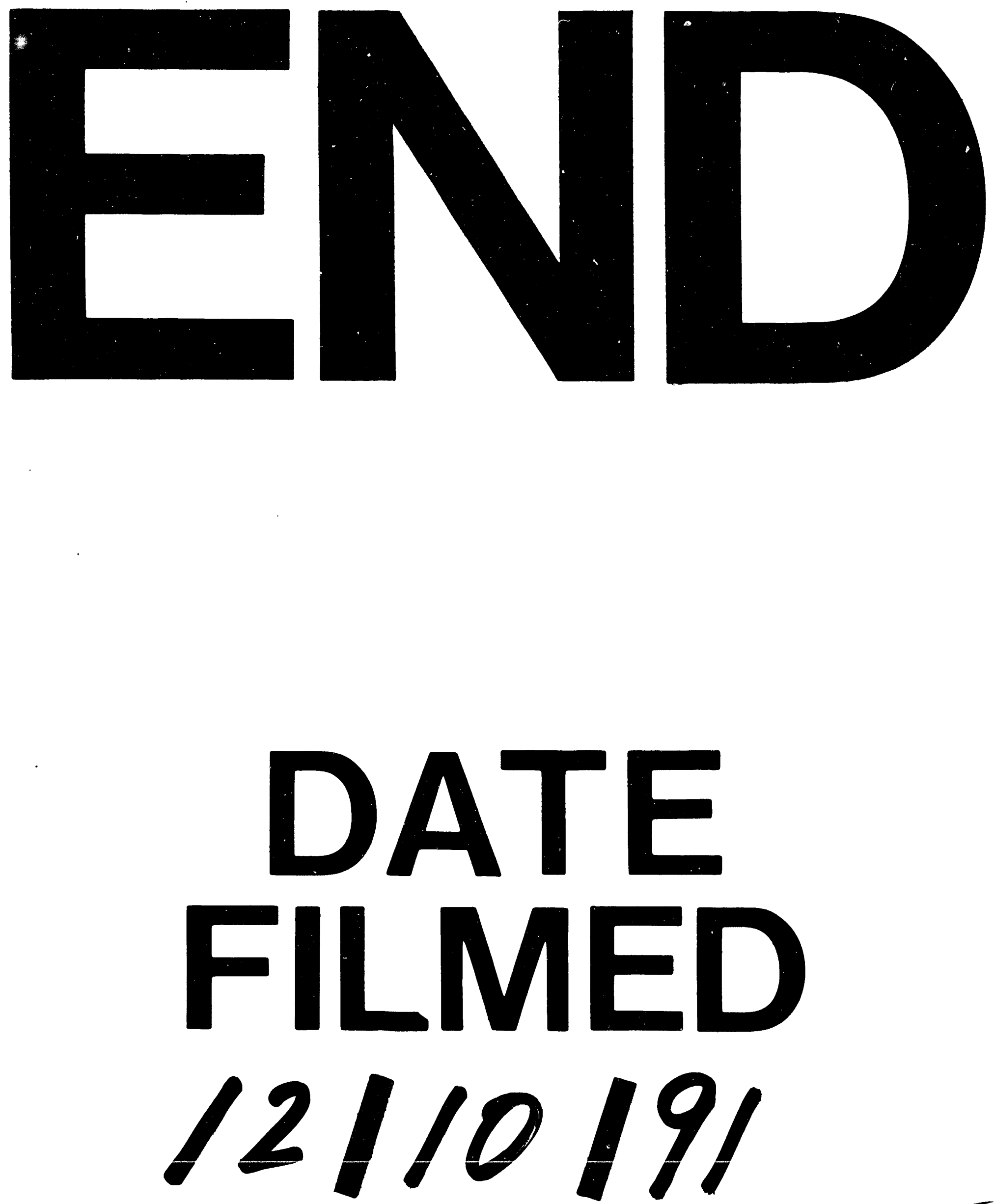
